\title{
Ginsenoside Rk1 bioactivity: A systematic review
}

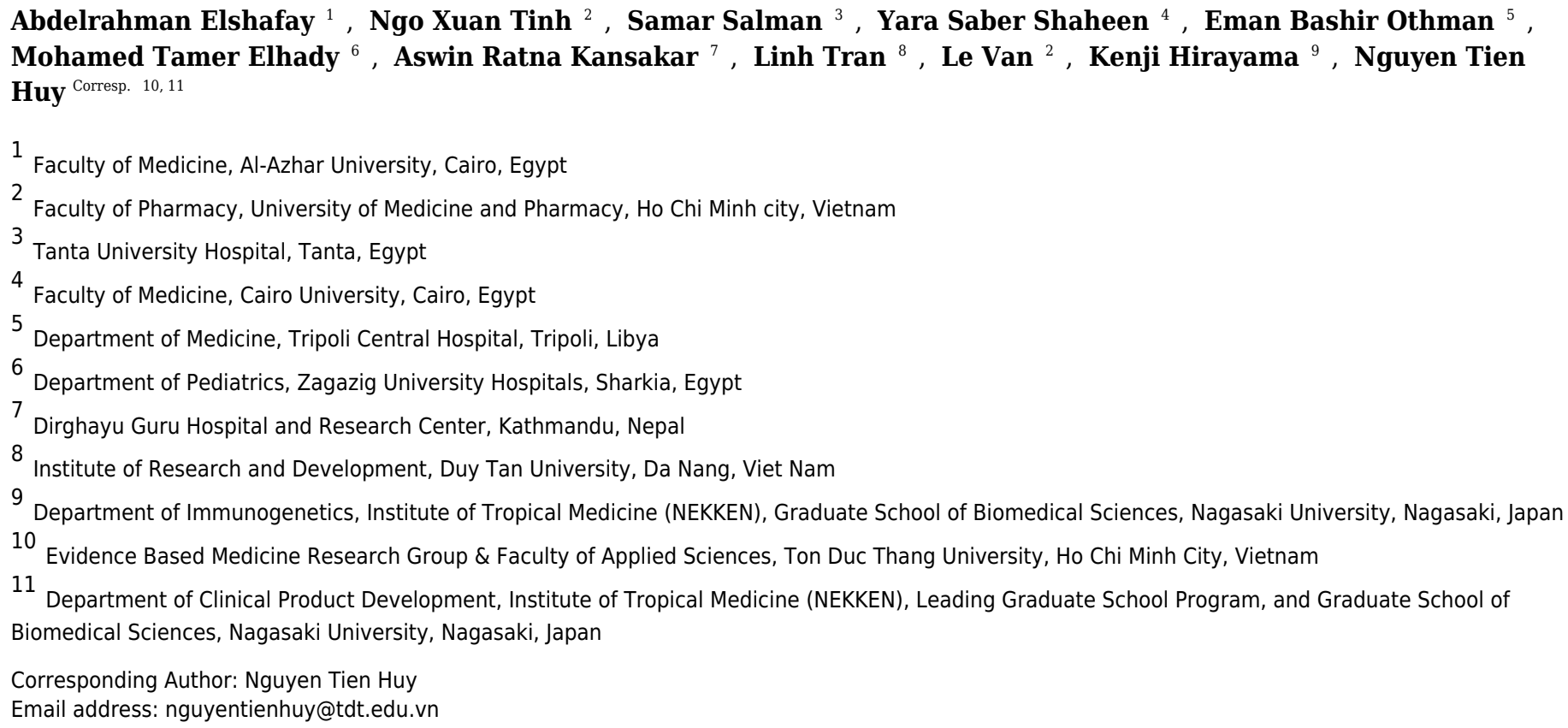

Ginsenoside Rk1 (G-Rk1) is a unique component created by processing Ginseng plant (mainly Sung Ginseng SG) at high temperatures. The aim of our study was to systematically review the pharmacological effects of G-Rk1. We utilized and manually searched eight databases to select in vivo and in vitro original studies that provided information about biological pharmaceutical effects of G-Rk1 and were published up to July 2017 with no restriction in language or study design. Out of the 156 papers identified we retrieved 28 eligible papers in the first skimming phase of research. Several articles largely described the G-Rk1 anti-cancer activity investigating "cell viability", "cell proliferation inhibition", "apoptotic activity", and "effects of G-Rk1 on G1 phase and autophagy in tumor cells", either alone or in combination with G-Rg5. Others proved that it has antiplatelet aggregation activities, anti-inflammatory effects, anti-insulin resistance, nephroprotective effect, antimicrobial effect, cognitive function enhancement, lipid accumulation reduction and prevents osteoporosis. In conclusion, G-Rk1 has a significant anti-tumor effect on liver cancer, melanoma, lung cancer, cervical cancer, colon cancer, pancreatic cancer, gastric cancer, and breast adenocarcinoma against in vitro cell lines. In vivo experiments are further warranted to confirm these effects. 


\section{Ginsenoside Rk1 bioactivity: A systematic review.}

2 Running title: A systematic review of ginsenoside Rk1 bioactivity.

3 Abdelrahman Elshafay ${ }^{1}$, Ngo Xuan Tinh ${ }^{2}, S_{\text {Samar Salman }}^{3}$, Yara Saber Shaheen ${ }^{4}$, Eman

4 Bashir Othman ${ }^{5}$, Mohamed Tamer Elhady ${ }^{6}$, Aswin Ratna Kansakar ${ }^{7}, \operatorname{Linh}_{\text {Tran }}^{8}, \operatorname{Le~Van}^{2}$,

5 Kenji Hirayama ${ }^{9}$, Nguyen Tien Huy ${ }^{10,11, *}$

$6 \quad{ }^{1}$ Faculty of Medicine, Al-Azhar University, Cairo, Egypt

$7 \quad{ }^{2}$ Faculty of Pharmacy, University of Medicine and Pharmacy, Ho Chi Minh city, Viet Nam

$8{ }^{3}$ Tanta University Hospital, Tanta, Egypt

$9 \quad{ }^{4}$ Faculty of Medicine, Cairo University, Egypt

10 5epartment of Medicine, Tripoli central Hospital, Tripoli, Libya

$11{ }^{6}$ Department of pediatrics, Zagazig University Hospitals, Sharkia, Egypt

$12 \quad{ }^{7}$ Dirghayu Guru Hospital and Research Center, Chabahil, Kathmandu, Nepal

13 'Institute of Research and Development, Duy Tan University, Da Nang, Vietnam

$14{ }^{9}$ Department of Immunogenetics, Institute of Tropical Medicine (NEKKEN), Graduate School of

15 Biomedical Sciences, Nagasaki University, 1-12-4 Sakamoto, Nagasaki, Japan

$16{ }^{10}$ Evidence Based Medicine Research Group \& Faculty of Applied Sciences, Ton Duc Thang University,

17 Ho Chi Minh City, Vietnam

$18{ }^{11}$ Department of Clinical Product Development, Institute of Tropical Medicine (NEKKEN), Leading

19 Graduate School Program, and Graduate School of Biomedical Sciences, Nagasaki University, Nagasaki,

20 Japan

$21{ }^{*}$ Correspondence to:

22 Nguyen Tien Huy, Evidence Based Medicine Research Group \& Faculty of Applied Sciences, Ton Duc

Thang University, Ho Chi Minh City, Vietnam 
24 (E-Mail: nguyentienhuy@tdt.edu.vn)

25 Emails:

26 Elshafay A: Abdelrahman.elshafay@azhar.edu.eg (ORCID: 0000-0002-6562-6341)

27 Tinh N X: tinhngo1209@gmail.com

28 Salman S: $\underline{\text { samarsalah21@yahoo.com }}$

29 Shaheen Y S: Yara3009@gmail.com

30 Othman E B: eman85otman@Gmail.com

31 Elhady M T: Mtielhd@gmail.com

32 Kansaker A R: kan.aswin@gmail.com

33 Tran L: $\underline{\text { linh.bioinfo@gmail.com }}$

34 Van L: levan@uphcm.edu.vn

35 Hirayama K: hiraken@nagasaki-u.ac.jp (ORCID: 0000-0001-9467-1777)

36 Huy N T: $\underline{\text { tienhuy@nagasaki-u.ac.jp (ORCID: 0000-0002-9543-9440) }}$ 
38 Abstract

39 Ginsenoside Rk1 (G-Rk1) is a unique component created by processing Ginseng plant (mainly

40 Sung Ginseng SG) at high temperatures. The aim of our study was to systematically review the

41 pharmacological effects of G-Rk1. We utilized and manually searched eight databases to select

42 in vivo and in vitro original studies that provided information about biological pharmaceutical

43 effects of G-Rk1 and were published up to July 2017 with no restriction in language or study

44 design. Out of the 156 papers identified we retrieved 28 eligible papers in the first skimming

45 phase of research. Several articles largely described the G-Rk1 anti-cancer activity investigating

46 “cell viability", "cell proliferation inhibition", "apoptotic activity", and "effects of G-Rk1 on G1

47 phase and autophagy in tumor cells", either alone or in combination with G-Rg5. Others proved

48 that it has antiplatelet aggregation activities, anti-inflammatory effects, anti-insulin resistance, nephroprotective effect, antimicrobial effect, cognitive function enhancement, lipid accumulation reduction and prevents osteoporosis. In conclusion, G-Rk1 has a significant anti-tumor effect on

51 liver cancer, melanoma, lung cancer, cervical cancer, colon cancer, pancreatic cancer, gastric 52 cancer, and breast adenocarcinoma against in vitro cell lines. In vivo experiments are further 53 warranted to confirm these effects. 


\section{Introduction}

Ginseng is commonly known as a medicinal herb, that is obtained from the roots of genus Panax (Shin et al. 2015). Ginseng belongs to one of the most ancient herbs in traditional medicine and is still widely used today (Choi et al. 2013). Ginsenosides are classified based on the steroidal structure and the number of hydroxyl groups/sugar moieties attached to it, such as protopanaxadiol, protopanaxatriol, oleanolic acid (or aglycone oleanolic acid) and ocotillol (Nag et al. 2015). The protopanaxadiol group includes Rb1, Rb2, Rb3, Rc, Rd, Rg3, Rh2, Rs1 and Rk1. The protopanaxatriol group includes $\mathrm{Re}, \mathrm{Rf}, \mathrm{Rg} 1, \mathrm{Rg} 2$, and $\mathrm{Rh} 1$ (Kim et al. 2013b). Ro is classified as oleanolic acid group (Tachikawa et al. 1999). details of types of ginsenosides are presented in Figure 1.

The quality and composition of ginsenosides in the Ginseng plant are affected by a range of factors such as species, age, part of the plant itself, method of cultivation, harvesting season and preservation methods (Lim et al. 2005; Schlag \& McIntosh 2006). Some of the ginsenosides, e.g Rk1, Rg3, Rg5, F4. are isolated from the heat-processed Ginseng, Sun Ginseng (SG), but are not detected in raw or air-dried ginseng (Kim et al. 2000).

Ginsenosides are widely known to have many pharmacological activities (Choi 2008; Ernst 2010) such as anti-tumor, anti-inflammatory (Chen et al. 2007), anti-fatigue (Tang et al. 2008) and analgesic effects (Nemmani \& Ramarao 2003).

Ginseng plant is commonly harvested after four to six years of cultivation and is divided in three types based on the processing methods: (1) fresh ginseng which is less than four years old, (2) white ginseng from four to six years and is oven dried after peeling, (3) red ginseng which is six years and steamed before drying. These processing methods aim to improve the efficacy, safety, and preservation (Yun 2001). SG was recently developed by heat-treatment at 
high temperature and pressure, which were higher than those applied to the conventional preparation of red ginseng.

SG has showed higher concentrations of less polar ginsenosides, which were either entirely absent or present in trace amounts in conventional red ginseng (Keum et al. 2000; Kwon et al. 2001).

The ginsenoside Rk1 (G-Rk1) is one of the main elements of SG (Kim et al. 2008).

Various studies confirmed the anti-cancer effects of G-Rk1 on several neoplastic such as hepatocellular carcinoma and melanoma (Kim et al. 2012; Kim et al. 2008). In recent studies, GRk1 was confirmed as a new endothelial barrier enhancer, which is capable of preventing or even blocking the vascular endothelial growth factor (VEGF)-induced vasopermeability in the endothelial cells. This presents the potential of developing pharmaceuticals that may effectively control pathologic vascular leakages (Maeng et al. 2013). Therefore, we aimed to systematically review the bioactivities of G-Rk1 in both human and animals.

\section{Methods}

\section{Protocol and registration}

The Preferred Reporting Items for Systematic Reviews and Meta-Analysis (PRISMA) Checklist (Moher et al. 2009) was followed in this systematic review. Our protocol was registered at PROSPERO CRD42016029129 in January 2016.

\section{Eligibility criteria}

We selected only original studies published up to July 2017 that provided information about the biological and pharmaceutical effects of G-Rk1. We included articles with G-Rk1 biological effects on human and animals either in vivo or in vitro with no restriction regarding publication language, publication date, or study design.

We excluded three main types of studies which are: 1-Studies with unreliable extracted 
102 data or overlapping data set, 2- Studies with only abstract available or no full-text available, 3-

103 Books, reviews, meta-analysis studies, conference papers, and thesis. Any disagreement was

104 discussed carefully among three reviewers to get a final decision.

105

106

107

108

109

110

111

\section{Information sources and search strategies}

We conducted electronic searches using eight databases which include: PubMed, Scopus, ISI Web of Science, Google Scholar, SIGLE (System for Information on Grey Literature in Europe), Virtual Health Library (VHL), World Health Organization Global Health Library (GHL), and POPLINE. A Manual search using reference lists of studies was preformed to find more relevant studies. The search strategy was performed by (AE, NXT, SS, YSS, EBO, MTE, ARK) and more information on search strategy was provided in S1 Table.

\section{Study selection}

We selected articles in two phases: 1. Title and abstract screening of all searched articles, 2. Full-text screening. The articles which were not in agreement with our inclusion and exclusion criteria were excluded. Three independent reviewers completed these two selecting phases. When disagreement occurred, a consensus decision was made following a discussion with supervisor $(\mathrm{NTH})$.

\section{Data collection process and data items}

We prepared our primary extraction form, extracted three papers with it one by one, modified our form after each paper extraction and finally developed the extraction sheet that we used on the remaining articles. Three independent reviewers extracted the data from each paper. A discussion among the three reviewers was held to reach a consensus whenever there was a disagreement in any information retrieved. If three reviewers could not come to an agreement, the supervisor $(\mathrm{NTH})$ was consulted.

The extracted data items included the last name of the first author, year of publication, 
126 year of subject recruitment, journal name, study design, country and city of origin of cell lines,

127 the name of the plant, and method of extraction of our targeted material (G-Rk1). If the study

128 included animals, we extracted their species, sex, age and weight. if it had been done in vivo, we

129 extracted the name of the cell line, its origin, the main medium used in terms of either primary

130 (isolated by authors) or commercial cell lines. Also, we extracted the name of the measured

131 parameter, an assay for its measurement, time effect, administration time, active substance name,

132 its concentration, mean, standard deviation, standard error, a $P$ value of results and the statistical

133 test. When the data was presented as graphs, we used Web blot digitizer software, and the

134 average of the results from three reviewers was calculated to obtain one result.

135 Risk of bias in individual studies

136 Two independent reviewers assessed all of the selected studies according to the GRADE

137 method (Guyatt et al. 2011) to judge the quality of evidence, and any disagreement was resolved

138 by discussion between them. Items such as limitation, inconsistency, indirectness, imprecision,

139 publication bias, and moderate or large effect size were to be scored as " 1 " if there is no serious

140 limitation or " 0 " if there is a serious limitation that has been defined according to GRADE

141 criteria. Then the overall quality was to be scored as "high", "moderate", "low", or "very low"

142 quality, according to their analysis of each study. The supervisor (NTH) was consulted when a

143 disagreement occurs.

144 Summary measures

145 Inhibition of cell proliferation, apoptosis, and regulation of protein expression were the 146 main evaluated outcomes.

147 Results

148 Study selection 
We identified 317 citations using the search strategy. From these, we included 156

150

151

152

153

154

155

156

157

158

159

160

161

162

163

164

165

166

167

168

169

170

171

172 articles after removing the duplicates. After that, we examined the title, abstract and further

excluded 107 articles. We retrieved and evaluated the full-text of the remaining 49 articles, of

which 25 articles were excluded, leaving 24 articles that were eligible, in addition to four articles that were retrieved from manually searching the included references. A flowchart described in details the process of identification, inclusion, and exclusion of articles was presented in Figure 2.

\section{Study characteristics}

Out of the 28 studies included, 21 studies were related to the effectiveness of G-Rk1 only and seven studies were reported on the combined effects of G-Rk1 and G-Rg5. The most common study design was in vitro study with 22 studies (Ahn et al. 2016; Ju et al. 2012; Kang et al. 2007; Kang et al. 2006; Kim et al. 2012; Kim et al. 2009; Kim et al. 2008; Kim et al. 2013c; Ko et al. 2009; Kwak \& Pyo 2016; Lee et al. 2009; Lee et al. 2010; Lee 2014; Lim et al. 2009; Liu et al. 2007; Park et al. 2002; Ponnuraj et al. 2014; Quan et al. 2015; Ryu et al. 2016; Siddiqi et al. 2014; Toh et al. 2011; Xue et al. 2017), while in vivo study was less common with only two studies (Jing et al. 2006; Kim et al. 2010). The remaining four articles were both in vitro and in vivo study (Bao et al. 2005; Hu et al. 2017; Maeng et al. 2013; Park et al. 2015). A summary of the included studies was presented in Table 1. For G-Rk1, bioactivities and mechanism of actions were summarized in Figure 3.

\section{Risk of bias across studies}

We used the GRADE method (Guyatt et al. 2011) to assess the quality of the included studies. Sixteen studies were categorized as high quality (Hu et al. 2017; Kang et al. 2006; Kim et al. 2009; Kim et al. 2008; Ko et al. 2009; Kwak \& Pyo 2016; Lee et al. 2009; Lee 2014; Lim et al. 2009; Liu et al. 2007; Maeng et al. 2013; Park et al. 2002; Quan et al. 2015; Ryu et al. 
173

174

175

176

177

178

179

180

181

182

183

184

185

2016; Toh et al. 2011; Xue et al. 2017). Twelve studies (Ahn et al. 2016; Bao et al. 2005; Jing et al. 2006; Ju et al. 2012; Kang et al. 2007; Kim et al. 2012; Kim et al. 2010; Kim et al. 2013c; Lee et al. 2010; Park et al. 2015; Ponnuraj et al. 2014; Siddiqi et al. 2014) were categorized as moderate quality. Seven of them (Ahn et al. 2016; Bao et al. 2005; Jing et al. 2006; Kim et al. 2013c; Park et al. 2015; Ponnuraj et al. 2014; Siddiqi et al. 2014) focused on the effectiveness of combined (G-Rk1, G-Rg5), thus, they were downgraded in indirectness item of GRADE factors. Three studies (Kang et al. 2007; Kim et al. 2010; Lee et al. 2010) were not completely pertained to our main outcome since they did not concern mainly with G-Rk1. Four studies (Kang et al. 2006; Lim et al. 2009; Liu et al. 2007; Park et al. 2002) were not downgraded in spite of having insufficient data regarding dose effect factor as this factor does not belong to the downgraded factors of GRADE method that include (limitation, inconsistency, indirectness, and Imprecision). In contrast, one study (Lee et al. 2010) that was downgraded since it focused on combined (GRk1 and G-Rg5) not because of dose effect insufficient data. Another study (Kim et al. 2012) was downgraded because it was used to compare the anti-tumor activity of G-Rk1 versus G-Rk3. However, G-Rk3 has been proven to have a potential antitumor activity. One study (Ju et al. 2012) was downgraded as it has statistical typing mistake of one of its values (S2 Table).

\section{Synthesis of results}

\section{Anti-cancer activity}

Cell viability was measured by different assays through the studies including four studies used Cell Counting Kit-8 (CCK8) assay (Kim et al. 2012; Kim et al. 2008; Kim et al. 2013c; Ko et al. 2009), five studies used 3-(4,5-dimethyl-thiazol-2yl) -2,5-diphenyl tetrazolium bromide (MTT) assay (Kwak \& Pyo 2016; Lee et al. 2010; Park et al. 2002; Quan et al. 2015; Siddiqi et al. 2014), and one study that used WST-1 assay (Toh et al. 2011) while the final one used EZCytoTox cell assay kit (Park et al. 2015). (Table 2) 


\section{Liver cancer}

Toh et al. in 2011, (Toh et al. 2011) evaluated the inhibitory effects of G-Rk1 $(0.25 \mu \mathrm{g} / \mathrm{ml})$ on cell growth of liver cancer cell lines (human hepatocellular carcinoma cells (HepG2), SNU449, and SNU182). A significant reduction of cell viability caused by G-Rk1 at $0.25 \mathrm{mg} / \mathrm{ml}$ was recorded $(\mathrm{p}<0.001)$. The inhibition concentration $\left(\mathrm{IC}_{50}\right)$ value of $\mathrm{G}-\mathrm{Rk} 1$ for inhibiting growth in the SNU449 cell line for $48 \mathrm{~h}$ was evaluated $0.08 \mathrm{mg} / \mathrm{ml}(100 \mu \mathrm{M})$ by using the WST-1 assay. These results indicated that G-Rk1 is one of the most anti-proliferative ginsenosides of raw and steamed P. notoginseng. Similarly, Quan et al., 2015 revealed that the HepG 2 cell viability was reduced to $23 \%$ and $15 \%$ compared to the vehicle control when treated with G-Rk1 at $40 \mu \mathrm{M}$ and $80 \mu \mathrm{M}$ for 24h, respectively (Quan et al. 2015).

Ko et al. in 2009, (Ko et al. 2009) evaluated the effect of G-Rk1 on cell viability of HepG2 cells after $24 \mathrm{~h}$ incubation in concentrations of $50,75,100 \mu \mathrm{M}$ in the presence of $0.1 \mu \mathrm{M}$ taxol which was used as a positive control. Compared with the vehicle control, G-Rk1 (at a dose of $100 \mu \mathrm{M}$ ) inhibited HepG2 cell proliferation by about $40 \%$. When HepG2 cells were exposed to various concentrations of G-RK1 for $24 \mathrm{~h}$ (from 50 to $100 \mu \mathrm{M}$ ), the inhibitory effect on growth rate raised significantly, from 8 to $37.5 \%$, in a dose-dependent manner. In addition, the cell viability was also tested when bafilomycin A1 was added to G-Rk1 $(100 \mu \mathrm{M})$ and then, three independent experiments showed that this co-treatment enhanced HepG2 cell death more than the cells that were treated with $100 \mu \mathrm{M}$ of G-Rk1 alone. In this experiment, to verify the effects of this combination and exclude cytotoxicity of bafilomycin A1, cytotoxicity was measured after $24 \mathrm{~h}$ and no cytotoxicity was detected.

In the study of Kim et al., in 2008, (Kim et al. 2008), they assessed the effects of G-Rk1 on cell viability of HepG2 cells. The concentrations of G-Rk1 ranging from 12.5 to $100 \mu \mathrm{M}$ with $0.5(\mathrm{v} / \mathrm{v})$ dimethyl sulphoxide added as control and incubated the cells for $48 \mathrm{~h}$ were used in this 
221 study. At 75 and $100 \mu \mathrm{M}$ of G-Rk1, the effect of G-Rk1 induced cell death was maximized to

$22255 \%$ and $95 \%$ cell death respectively. In addition, the results revealed that the treatment of

223 HepG2 cells with $100 \mu \mathrm{M}$ G-Rk1, the fraction of early apoptotic cells increased from 0.46 to

$224 \quad 16.23 \%$ and the underlying mechanism by which G-Rk1 induces the mitochondria-independent

225 apoptosis can be through the activation of capspase-8, the signaling cascade of the one not

226 associated with Fas-associated death domain expression.

227

228

229

230

231

232

233

234

235

236

237

238

239

240

241

242

243

244

To increase their cytotoxicity against Sk-Hep-1 hepatoma cancer cells, Park et al. in 2002, (Park et al. 2002) used steamed ginseng which was separated by HPLC and tested with

MTT assay to produce many active ginsenosides including G-Rk1. In this study, they found that the isolated G-Rk1 was associated with an inhibitory effect on cell viability in Sk-Hep1 cells. The growth inhibition concentration of G-Rk1 was $13 \mu \mathrm{M}$.

\section{Lung cancer}

G-Rk1 was evaluated in human lung cancer A549, and cell viability (\% to control) was assessed using MTT assay. At the concentration of $50 \mu \mathrm{M}$, there was a statistically significant difference between cisplatin treated cell lines and Rk1 treated cell lines. However, G-Rk1 showed approximately 2 times higher anticancer activity than $\operatorname{Rg} 5$ when treated at $100 \mu \mathrm{M}$. After $24 \mathrm{~h}$ treatment, the IC50 values of G-Rk1 and cisplatin were 70 , and $50 \mu \mathrm{M}$, respectively. Several proteins were found to be related to the apoptotic effect of G-Rk1 such as calmodulin-like protein, purine nucleoside phosphorylase, adaptor molecular crk, and transaldolase enzyme were increased while biliverdin reductase, aldehyde dehydrogenase, dihydropteridine reductase, and transactive response DNA binding protein-43 were decreased (Kwak \& Pyo 2016). In another study, A549 cell viability was reduced to $47 \%$ and $3.6 \%$ compared to the vehicle control when treated with G-Rk1 at $40 \mu \mathrm{M}$ and $80 \mu \mathrm{M}$ for 24h, respectively (Quan et al. 2015).

\section{Melanoma}


To evaluate the inhibitory effect on cell viability of SK-Mel-2 human melanoma cells,

246

247

248

249

250

251

252

253

254

255

256

257

258

259

260

261

262

263

264

265

266

267

268

Kim et al. in 2012, (Kim et al. 2012) incubated these cells with G-Rk1 for 24 and 48h at different

concentrations $(0,10,25,50,75,100 \mu \mathrm{M})$ in a dose-dependent manner. Erb et al. (Erb et al.

2005 ) in 2005, provoked a controversy with the role of FAS and/or FASL in human malignant

melanoma. Therefore, the effect of FAS and/or FASL on cell viability was evaluated by Kim et

al. (Kim et al. 2012) by adding Fas/FasL antagonist Kp 7-6 of concentration 1mM and incubated

it for $1 \mathrm{~h}$. Then, the cells were treated with various concentrations of G-Rk1 $(1,5,10,50$ and 100

$\mu \mathrm{M})$. The results showed that Kp 7-6 treatment alone did not induce cell death or cell

proliferation. Therefore, they concluded that Kp 7-6 has no effect on cell viability when used

alone. However, when the cells were treated by Kp7-6 followed by G-Rk1 (100 $\mu \mathrm{M})$ treatment,

the effect of G-Rk1 was reduced by $32 \%$ compared to the control (no treatment of Kp7-6).

Moreover, they also assessed the induction of apoptosis by G-Rk1 in SK-MEL-2-Human

Melanoma and their findings showed that when the concentration of G-Rk1 increased, the

number of apoptotic cells also increased. More importantly, the cell lines responded in a dosedependent manner.

\section{Other types of cancer}

Kim et al. (Kim et al. 2013c) evaluated the effect of the combination of G-Rg5/G-Rk1 on cell viability of gastric cancer cells. After treatment with this combination at different concentrations $(12.5,25,50$ and $100 \mu \mathrm{M})$ for $24 \mathrm{~h}$, the results showed an inhibitory effect on cell viability and proliferation of these cells in a dose-dependent manner $(99,93.5,37.5,3 \%)$ respectively. In another study, cell viability was assessed using different cancer cell lines including human colon carcinoma (HCT-116), human cervical carcinoma (Hela), human breast adenocarcinoma (MCF-7), and human pancreatic cancer (PANC-1). When they were treated with $80 \mu \mathrm{M}$ of G-Rk1, cell viability was reduced by $5.4 \%, 11 \%, 8.6 \%$, and $9.9 \%$, respectively 
269 (Quan et al. 2015).

270 Antiplatelet aggregation activity

Two studies evaluated the anti-aggregation effects of G-Rk1 both in vivo and in vitro (Ju

272

273

274

275

276

277

278

279

280

281

282

283

284

285

286

287

288

289

290

291

292

et al. 2012; Lee et al. 2009) respectively. Ju et al. compared the antiplatelet aggregation activity of G-Rk1 and acetylsalicylic acid (ASA) (Ju et al. 2012). The results indicated that G-Rk1

exhibits a stronger antiplatelet aggregation activity than ASA in which the action of G-Rk1 in platelets might be related to arachidonic acid (AA) metabolism. In addition, the alteration of (S) hydroxyl eicosatetraenoic acids and thromboxane B2 levels were determined using an immunoassay kit and UPLC/Q-TOF MS system, respectively. The 12-hydroxyleicosatetraenoic acid level was remarkably decreased in the G-Rk1 group but increased in the ASA-treated group. The thromboxane B2 level in the washed platelets decreased significantly by $66 \%$ when treated with $100 \mu \mathrm{M}$ ASA and 77\% when treated with $10 \mu \mathrm{M} \mathrm{G-Rk1} \mathrm{(Ju} \mathrm{et} \mathrm{al.} \mathrm{2012).} \mathrm{They} \mathrm{used} \mathrm{the}$ colorimetric COX inhibitor screening assay to measure the inhibitory effects of G-Rk1 on COX1 and COX-2. It was found that G-Rk1 inhibits both COX-1 and COX-2 activities. However, at a concentration of $20 \mu \mathrm{M}$, G-Rk1-derived inhibition was higher on COX-2 than on COX-1 (Ju et al. 2012).

Lee et al. explained in his study (Lee et al. 2009) that the effect of G-Rk1 on adenosine diphosphate (3-4 $\mu \mathrm{M})$ induced platelet aggregation was monitored turbidimetrically by using ASA as a positive control. Both ASA and G-Rk1 showed the dose-dependent inhibitory effect on collagen, AA and U46619 (9,11-dideoxy-11a,9a-epoxymethanoprostaglandin F2a) (thromboxane A2 mimetic drug)-induced platelet aggregation. However, they showed a negligible effect on adenosine diphosphate-induced aggregation. G-Rk1 exhibited the strongest inhibitory effect on collagen, AA, and U46619-induced platelet aggregation. In particular, it presented a 22-fold activity of ASA on AA-induced aggregation (Lee et al. 2009). G-Rk1 was found to be a potent 
293 inhibitor of AA and U46619 -induced platelet aggregation. (Table 3)

\section{Anti-inflammatory activity}

295

296

297

298

299

300

301

302

303

304

305

306

307

308

309

310

311

312

313

314

315

316

G-Rk1 was found to have an anti-inflammatory effect by inhibit NF- $\kappa B$ levels in the in vitro models (Lee 2014). These results were assessed using luciferase assay. HepG2 cells were seeded at $1 \times 10^{5}$ cells/well in a 12 -well plate and grown for $24 \mathrm{~h}$. While G-Rk1 was pretreated with dimethyl sulphoxide for $1 \mathrm{~h}$ and then it was treated with tumor necrosis factor- $\alpha(10 \mathrm{ng} / \mathrm{mL})$, the sulfasalazine was used as positive control. Their data demonstrated the strong inhibitory activity of G-Rk1 on NF- $\mathrm{BB}$ expression with $50 \%$ (IC50) value from $0.75 \mu \mathrm{M}$. However, the results revealed that G-Rk1 had cytotoxic effects, which occur in concentrations higher than 10 $\mu \mathrm{M}$. Another evaluation of G-Rk1 anti-inflammatory activity (Kim et al. 2010), was its suppressing effect on 12-O-tetradecanoyl- phorbol-13-acetate (TPA) induced mouse ear edema. The right ear of ICR mouse was treated with red ginseng saponin extract, G-Rg3, G-Rg5, and G$\mathrm{Rk} 1$ of 10 , and $50 \mathrm{mg} / \mathrm{kg}$ and after 30 minutes, ear edema in both ears was induced by topical application of TPA, which is a potent inflammatory agent. They measured the extent of edema and noticed that the pretreatment with red ginseng saponin extract or G-Rk1 suppresses TPAinduced mouse ear edema, and when administering G-Rk1 orally, the formation of edema was blocked. Hu et al., in 2017, showed that in acetaminophen (APAP) induced liver injury in mice, G-Rk1 can be used as a protective agent, as it significantly reduced the levels of tumor necrosis factor (TNF- $\alpha$ ) to $87 \mathrm{ng} / \mathrm{L}$ and when treated with $10 \mathrm{mg} / \mathrm{kg} \mathrm{G}-\mathrm{Rk} 1$ compared to $156 \mathrm{ng} / \mathrm{L}$ when treated with $250 \mathrm{mg} / \mathrm{kg}$ APAP. A significantly reduction of interleukin-1 $\beta$ (IL-1 $\beta$ ) was observed with G-Rk1 (Hu et al. 2017). Atopic dermatitis in which keratinocytes and macrophages produce excess chemokines and cytokines, especially thymus and activation-regulated chemokine (TARC/CCL17) and macrophage-derived chemokine (MDC/CCL22), as well as nitric oxide (NO), Ahn's results using G-Rg5/G-Rk1 on TNF- $\alpha /$ IFN- $\gamma$ stimulated human keratinocytes cell 
317 line (HaCaT cells) showed a significant reduction of TARC/CCL17 expression. Furthermore,

318 using the same combination on the murine macrophage cell line RAW264.7, the secretion of

319 lipopolysaccharide (LPS) mediated NO and reactive oxygen species were significantly reduced,

320 Suggesting G-Rg5/G-Rk1 as a promising natural therapy in the control of atopic dermatitis (Ahn

321 et al. 2016).(Table 3)

322 Effect of G-Rk1 on vascular leakage

323

324

325

326

327

328

329

330

331

332

333

334

335

336

337

338

339

340

A study evaluated the G-Rk1 effect on VEGF (Maeng et al. 2013) by treating primary

human retina microvascular endothelial cells with G-Rk1 at a concentration of $(10 \mu \mathrm{g} / \mathrm{ml})$ for 40 minutes then stimulating it with $20 \mu \mathrm{g} / \mathrm{ml}$ of VEGF to disrupt the cell membrane. Sucrose permeability assay was used to evaluate the endothelial permeability and the results showed that G-Rk1 inhibited VEGF-induced retinal endothelial permeability. They used reverse-transcription polymerase chain reaction (RT-PCR) and densitometric analysis was used to assess translocation of tight junctions (TJ) proteins, and immunostaining was used to evaluate disruption of TJ proteins after the cells were stained with anti-ZO-1, anti-ZO-2, and anti-occludin antibodies. The authors found that G-Rk1 inhibited VEGF effect on TJ protein localization but it did not affect the transcription of TJ proteins. (Table 3)

\section{Effect of G-Rk1 on lipid accumulation}

The Ginseng was known to have effects on obesity (Kim et al. 2009). In vitro treatment of mouse 3T3-L1 fibroblast cells with G-Rk1 resulted in reducing lipid accumulation, in which these cells differentiated into adipocytes after being treated with with various G-Rk1 concentrations $(10,50,100 \mu \mathrm{M})$ for $2 \mathrm{~h}$ at $490 \mathrm{~nm}$ optical absorbance (Kim et al. 2009) (Table 3).

\section{Neuroprotective effect of G-Rk1}

The combination of G-Rg5/G-Rk1 had a pronounced effect on the excitotoxic and oxidative stress-induced neuronal cell damage that was tested in primary cultured rat cortical 
341 cells (Bao et al. 2005). These cells were cultured in vitro for 12-20 days, then exposed to $100 \mu \mathrm{M}$

342 glutamate or N-methyl-D-aspartate for $15 \mathrm{~min}$ in the absence or presence of G-Rg5/G-Rk1. The

343 cell damage was assessed after 20-24h by measuring LDH activity in the culture media. Data

344 was calculated from cells exposed to the respective excitotoxic insults without ginsenosides.

345 Data presented that approximately $70-80 \%$ of the cells were damaged by glutamate or N-methyl-

346 D-aspartate compared to vehicle-treated control cells. The excitotoxic effect was significantly

347 inhibited by G-Rg5/G-Rk1 in a concentration-dependent manner, in which 50\% inhibition was

348 achieved at $14.7 \mu \mathrm{g} / \mathrm{mL}$ of G-Rg5/G-Rk1.

349 In previous work, Bao et al. (Bao et al. 2005) used a passive avoidance test to evaluate

350 the effect of G-Rg5/G-Rk1. The latency in seconds was used to measure the cognitive

351 performance of ethanol-induced amnesia in mice. The mice were orally treated with saline as

352 vehicle and ratio of G-Rg5/G-Rk1 equal $1: 1$ with a concentration of $10 \mathrm{mg} / \mathrm{kg}$ once a day for 4

353 days. The latency period of the mice administrated with ethanol was $24.9 \%$ less than the 1 of

354 control mice (without ethanol-treatment), but it was significantly enhanced by the oral

355 administration of G-Rg5/G-Rk1 with 1.2-fold increase than that of the control. The same steps

356 were done but this time after inducing amnesia with a single injection of scopolamine (3 $\mathrm{mg} / \mathrm{kg})$,

357 also G-Rg5/G-Rk1 (10 mg/kg) provided the same enhancing significant result $(\mathrm{p}<0.01)$. In

358 another work, Jing et al. (Jing et al. 2006) did the same tests of ethanol-induced amnesia in mice,

359 which were given water as the control and ratio of G-Rg5/G-Rk1 equal 1:1 in the concentration

360 of $10 \mathrm{mg} / \mathrm{kg}$. They found that G-Rg5/G-Rk1 could significantly prolong the latency period by

3612.97 folds more than that of the control. These two studies presented that G-Rg5/G-Rk1 would

362 give beneficial results in the memory function of the normal, ethanol or scopolamine-induced

363 amnesia in brains. G-Rk1 was reported to have a significant neurogenic activity in Epidermal

364 growth factor-responsive neurosphere stem cells (erNSCs). However, this activity was less than 
365

366

367

368

369

370

371

372

373

374

375

376

377

378

379

380

381

382

383

384

385

386

387

388

G-Rg5 (Liu et al. 2007) (Table 3).

\section{Nephroprotective effect of G-Rk1}

Park et al. (Park et al. 2015) examined the effect of the G-Rg5/G-Rk1 combination on cisplatin-induced nephrotoxicity in mice at cisplatin concentration $25 \mu \mathrm{M}$ and G-Rg5/G-Rk1 concentrations of $(0,50,100,250 \mu \mathrm{g} / \mathrm{ml})$. Results with EZ-cytotoxic cell viability assay kit showed a significant reduction in cisplatin and induced a reduction in cell viability. This effect was higher than that of Epigallocatechin gallate at the same concentrations as G-Rk1 (Table 3).

\section{Bone metabolism}

Siddiqi et al. (Siddiqi et al. 2014) in 2014, evaluated the osteogenic activity of GRg5/G-Rk1. MC3T3-E1 cells were treated with differentiation medium (either with or without G-Rg5/G-Rk1) for 12 days at different concentrations in which different substances were added to the culture medium in order to evaluate various effects of G-Rg5/G-Rk1 on differentiated fibroblast. The extent of calcium deposition, which is an indicator of osteoblasts mineralization, was measured by MTT assay. Data were expressed as a percentage of control, which showed that G-Rg5/G-Rk1 protected the extracellular matrix mineralization from antimycin A devastating effects. Besides, it turned out that alkaline phosphatase (ALP) activity evaluated by Smart BCA protein assay kit, increased by two folds after treatment with G-Rg5/G-Rk1 (30-50 $\mu \mathrm{g} / \mathrm{mL})$. The effect of G-Rg5/G-Rk1 on cellular collagen was measured using Sirius Red-based colorimetric assay. Results were similar to that of ALP activity in which cellular collagen was markedly increased. When glutathione contents of the cells were measured by glutathione assay kit after exposure to various concentrations of G-Rg5/G-Rk1, data showed that G-Rg5/G-Rk1 increase the level of glutathione in a dose-dependent manner. In order to evaluate gene expression levels, a total RNA was isolated from the cells, which were treated with G-Rg5/GRk1 and was amplified by RT-PCR. The results indicated that the maturation and the 
differentiation of MC3T3-E1 cells were induced by G-Rg5/G-Rk1 mediated BMP-2/Runx2 and the level of expression of Runx2 increased by the action of G-Rg5/G-Rk1 (Table 3).

\section{Anti-insulin resistance effect of G-Rk1}

Ponnuraj et al., in 2014, (Ponnuraj et al. 2014) assessed the effect G-Rk1 on insulin resistance. 3T3-L1 cells were treated with G-Rg5/G-Rk1 complex at different concentrations where tunicamycin was used to induce stress on the endoplasmic reticulum (ER). As for cell viability, measured with MTT assay, results showed that cells treated with G-Rg5/G-Rk1 complex had overcome the stress which induced by tunicamycin. Cells were made insulin resistant by immersing them into a medium that contains insulin and by treating them with dexamethasone, then with stress agent and G-Rg5/G-Rk1 complex and were analyzed by glucose oxidase reagent, while tunicamycin was used as a positive control. Results found that the amount of glucose left in the medium is high in the cells treated with tunicamycin and low in the cells treated with G-Rg5/G-Rk1 complex and this was achieved through C/EBP homologus protein-10 (CHOP)-mediated pathway and increase insulin-like growth factor receptor (IGF-2R) (Table 3).

\section{Anti-oxidant effect of G-Rk1}

Hydrothermal treatment of primary ginsenosides at $100 \mathrm{C}$ transformed them into either deglycosylated and/or dehydrated ginsenoside. As the hypothermal reaction increase it yields more 20 (S)-Rg3, Rk1, and Rg5. In addition, when they compared the antioxidant activity between the hydrothermally processed samples at $100 \mathrm{C}$ and others processed by the steaming, they got results that showed that sun ginseng samples were higher in antioxidant activities. However, it results in fewer ginsenosides than those samples which reacted at $120 \mathrm{C}$ (Ryu et al. 2016).

\section{Antimicrobial effect of G-Rk1}

Xue et al., in 2017, (Xue et al. 2017) assessed the antimicrobial effect of G-Rk1 
413 measured by the minimum inhibitory concentration (MIC) and minimum bacterial concentration

414 (MBC). Compared to Erythrocin (positive control), G-Rk1 exhibited higher MIC and MBC

415 against different bacterial strains compared to Erythrocin (positive control) with (MIC: 31.3 vs 8

$416 \mu \mathrm{g} / \mathrm{ml}$; MBC: $125.0 \mathrm{vs} 16.0 \mu \mathrm{g} / \mathrm{ml}$ ) against Clostridium perfringens, (MIC: $16.0 \mathrm{vs} 8 \mu \mathrm{g} / \mathrm{ml}$;

417 MBC: 125.0 vs $31.3 \mu \mathrm{g} / \mathrm{ml}$ ) against Fusobacterium nucleatum, and (MIC: $62.5 \mathrm{vs} 16.0 \mu \mathrm{g} / \mathrm{ml}$;

418 MBC: 125.0 vs $62.5 \mu \mathrm{g} / \mathrm{ml}$ ) against Porphyromonas gingivalis. Therefore, G-Rk1 can be a

419 promising cure for halitosis.

\section{Discussions}

Ginsenosides are active compounds extracted from white or red ginseng (P. Ginseng Meyer). Ginsenosides have shown pharmacological effects on the cardiovascular system (Sun et al. 2016), the immune system (Song et al. 2009), and the central nervous system (Zhou et al. 2014), as well as anti-stress,antioxidant, and anti-cancer activities. Moreover, ginsenosides have shown good results in the treatment of diabetes disease by improving glucose and insulin control in type 2 diabetes in a clinical trial (Vuksan V et al. 2008). Antitumor inhibitory effects of ginsenosides have been demonstrated because of their cytotoxicities such as the suppression of tumor angiogenesis and metastasis by G-Rb2 (Sato et al. 1994) and the enhancement of apoptosis by G-Rg3 in various cancer cell lines such as breast cancer (Kim et al. 2013a). Although G-Rk1 has a similar structure to G-Rg3, G-Rk1 could be formed by processing ginseng at high temperature, but its antitumor activities would have been limited. Its pharmacological activity has been assessed on antitumor activity in human hepatocellular carcinoma cells (Kim et al. 2008). Apart from these activities, G-Rk1 has been demonstrated to ameliorate impaired memory function and prevent platelets aggregation (Lee et al. 2009). Furthermore, G-Rg3, GRk1, and G-Rg5 exhibited a potential effect in the management of human arthritis (Kim et al. 436 2010). 
In this systematic review, we found that various pharmacological and therapeutic effects

438

439

440

441

442

443

444

445

446

447

448

449

450

451

452

453

454

455

456

457

458

459

460

of G-Rk1 have been reported in the 28 included studies such as anti-cancer effects (Kim et al. 2008), antiplatelet aggregation activities (Ju et al. 2012; Lee et al. 2009), cognitive function enhancement (Bao et al. 2005), anti-inflammatory effects (Kim et al. 2010; Lee 2014), lipid accumulation reduction (Kim et al. 2009), antioxidant effects (Ryu et al. 2016), anti-insulin resistance (Ponnuraj et al. 2014), and protection against human arthritis and nephrotoxicity (Kim et al. 2010; Park et al. 2015).

Anti-cancer activity is one of the most common bioactivities of G-Rk1. By assessing such studies in "cell viability"/“cell proliferation inhibition" and "apoptotic activity", these studies exhibited the anti-cancer effects of G-Rk1 in in vitro studies as well as the combined effectof GRg5/G-Rk1 (ratio equal 1:1). In terms of "cell viability", the effects of G-Rk1 on cell viability of HepG2 cells, SNU449, SNU182, SK-Hep-1, SK-Mel-2, Hela, HCT-116, MCF-7, PANC-1, A549, and human malignant melanoma was found significantly in a dose-dependent manner (Kim et al. 2012; Kim et al. 2008; Ko et al. 2009; Kwak \& Pyo 2016; Quan et al. 2015). The concentrations of G-Rk1 vary from 0 to $100 \mu \mathrm{M}$, and the cytotoxic effect was maximum at 75 and $100 \mu \mathrm{M}$ (Kim et al. 2008). The effects of G-Rk1 were also evaluated in combination with other chemotherapeutics (Bafilomycin A1)(Ko et al. 2009).

It was found that the enhancement of HepG2 cell death was higher when applying GRg5/G-Rk1 combination than that of G Rk1 alone. Furthermore, we also found three relevant studies (Kim et al. 2013c; Park et al. 2015; Siddiqi et al. 2014) that evaluated the effects of GRg5/G-Rk1 co-treatment on cell viability of gastric cancer cells, mice, and MC3T3-E1 cells. The authors demonstrated that G-Rg5/G-Rk1 has potential effects on inhibiting cell viability and proliferation in a dose-dependent manner. The combination of G-Rg5/G-Rk1 with others chemotherapies (cisplatin (Park et al. 2015), antimycin A (Siddiqi et al. 2014)) has a greater 
461 effect on cell death than using G-Rg5 or G-Rk1 alone. Besides, it was also proved that co-

462 administration of G-Rg5/G-Rk1 with a ratio $1: 1$ have various effects such as improving the

463

464

465

466

467

468

469

470

471

472

473

474

475

476

477

478

479

480

481

482

483

484

cognitive performance in ethanol-induced amnesia in mice (Bao et al. 2005; Jing et al. 2006),

inhibiting the exotoxic and oxidative stress-induced neuronal cell damage (Bao et al. 2005), and

stimulating the mineralization of the extracellular matrix of osteoblasts (Siddiqi et al. 2014).

In this systematic review, we found two studies presenting the antiplatelet aggregation

activities with the results indicating that G-Rk1 $(10 \mu \mathrm{M})$ can be stronger than ASA $(100 \mu \mathrm{M})$

regarding the antiplatelet aggregation (Ju et al. 2012). Lee et al. in 2009, also showed that G-Rk1

inhibited the effects of collagen, AA, and U46619-induced platelet aggregation (Lee et al. 2009).

G-Rk1 was also indicated as one of the effective anti-inflammatory agents through the inhibition

of both COX1 and COX2 activities and NF- $\kappa B$ levels (Ju et al. 2012; Lee 2014).

Although, more than ten of our included studies reported that G-Rk1 has an anti-cancer

effect against different cancer cell lines, all of them were in vitro studies with no in vivo or

clinical studies. Unlikely, it was reported that G-Rg3 has anti-cancer effect in both in vitro and in vivo (Shan et al. 2014). A recent meta-analysis of randomized clinical trials revealed that G-Rg3 combined with chemotherapy for non-small-cell lung cancer could enhance the overall survival rate and alleviate the chemotherapy-induced side effects (Xu et al. 2016). The shortage of in vivo or clinical studies to assess the G-Rk1 anti-cancer effect may raise many questions regarding the effect of G-Rk1 in patients and will it differ from its in vitro action?. In addition, what alterations that may occur in the patients. Therefore, there is a need for in vivo experiments to confirm the G-Rk1 anti-cancer activity and its mechanism.

Regarding the methodological approaches several limitations were encountered. One of them is that we could not find any clinical study that used G-Rk1 in patients or healthy people. Out of 317 studies, we included 28 studies using our criteria they were in vitro studies and in 
485 vivo animals. Based on GRADE method, seven studies remained because of indirectness of 486 evidence (Ahn et al. 2016; Bao et al. 2005; Jing et al. 2006; Kim et al. 2013c; Park et al. 2015;

487 Ponnuraj et al. 2014; Siddiqi et al. 2014) and inability to explain heterogeneity in results (Bao et al. 2005). To date, there is a shortage of literature regarding clinical studies and the clinical use of G-Rk1 to treat some diseases in patients, and it consequently prohibits the clinical analysis.

\section{Conclusions}

In general, G-Rk1 has a significant anti-tumor effect on liver cancer, melanoma, lung cancer, cervical cancer, colon cancer, pancreatic cancer, gastric cancer, and breast adenocarcinoma against in vitro cell lines. Furthermore, In vivo experiments are necessary to confirm these effects. Additionally, G-Rk1 has demonstrated several pharmacological effects such as antiplatelet aggregation, anti-inflammatory, anti-oxidant, antimicrobial, anti-insulin resistance, neuroprotective, nephroprotective, and anti-lipid accumulation effects. All these results support the clinical effects of G-Rk1 and demonstrate the promising possibility to develop the G-Rk1-based treatments, either alone or in combination with G-Rg5, for the previously mentioned conditions.

\section{References}

Ahn S, Siddiqi MH, Aceituno VC, Simu SY, Zhang J, Perez ZE, Kim YJ, and Yang DC. 2016. Ginsenoside Rg5:Rk1 attenuates TNF- $\alpha /$ IFN- $\gamma$-induced production of thymus- and activation-regulated chemokine (TARC/CCL17) and LPS-induced NO production via downregulation of NF-kB/p38 MAPK/STAT1 signaling in human keratinocytes and macrophages. In Vitro Cell Dev Biol Anim 52:287-295.

Bao HY, Zhang J, Yeo SJ, Myung CS, Kim HM, Kim JM, Park JH, Cho J, and Kang JS. 2005. Memory Enhancing and Neuroprotective Effects of Selected Ginsenosides. Arch Pharm Res 28:335-342.

Chen LW, Wang YQ, Wei LC, Shi M, and Chan YS. 2007. Chinese herbs and herbal extracts for neuroprotection of dopaminergic neurons and potential therapeutic treatment of Parkinson's disease. CNS Neurol Disord Drug Targets 6:273-281.

Choi J, Kim TH, Choi TY, and Lee MS. 2013. Ginseng for health care: a systematic review of randomized controlled trials in Korean literature. PLoS One 8:e59978. 10.1371/journal.pone.0059978

Choi KT. 2008. Botanical characteristics, pharmacological effects and medicinal components of Korean Panax 
ginseng C A Meyer. Acta Pharmacol Sin 29:1109-1118. 10.1111/j.1745-7254.2008.00869.x

Erb P, Ji J, Wernli M, Kump E, Glaser A, and Buchner SA. 2005. Role of apoptosis in basal cell and squamous cell carcinoma formation. Immunol Lett 100:68-72.

Ernst E. 2010. Panax ginseng: An Overview of the Clinical Evidence. Journal of Ginseng Research 34:259-263. 10.5142/jgr.2010.34.4.259

Guyatt G, Oxman AD, Akl EA, Kunz R, Vist G, Brozek J, Norris S, Falck-Ytter Y, Glasziou P, DeBeer H, Jaeschke R, Rind D, Meerpohl J, Dahm P, and Schunemann HJ. 2011. GRADE guidelines: 1. Introduction-GRADE evidence profiles and summary of findings tables. $J$ Clin Epidemiol 64:383-394. 10.1016/j.jclinepi.2010.04.026

Hu JN, Xu XY, Li W, Wang YM, Liu Y, Wang Z, and Wang YP. 2017. Ginsenoside Rk1 ameliorates paracetamolinduced hepatotoxicity in mice through inhibition of inflammation, oxidative stress, nitrative stress and apoptosis. J Ginseng Res. https://doi.org/10.1016/j.jgr.2017.07.003

Jing Z, Shi-rong W, Quan-cheng C, Long PH, and Kang JS. 2006. Effects of Ginsenosides Rg3(R), Rg3(S)and Rg5/Rk1 on Memory Improvement of Ethanol Treated Mice. Journal of Jilin Agricultural University 28.

Ju HK, Lee JG, Park MK, Park SJ, Lee CH, Park JH, and Kwon SW. 2012. Metabolomic investigation of the antiplatelet aggregation activity of ginsenoside $\mathrm{Rk}(1)$ reveals attenuated 12-HETE production. $J$ Proteome Res 11:4939-4946. 10.1021/pr300454f

Kang KS, Kim HY, Baek SH, Yoo HH, Park JH, and Yokozawa T. 2007. Study on the Hydroxyl Radical Scavenging Activity Changes of Ginseng and Ginsenoside-Rb2 by Heat Processing. Biol Pharm Bull 30:724-728.

Kang KS, Kim HY, Yamabe N, and Yokozawa T. 2006. Stereospecificity in hydroxyl radical scavenging activities of four ginsenosides produced by heat processing. Bioorg Med Chem Lett 16:5028-5031. 10.1016/j.bmcl.2006.07.071

Keum YS, Park KK, Lee JM, Chun KS, Park JH, Lee SK, Kown H, and Surh YJ. 2000. Antioxidant and anti-tumor promoting activities of the methanol extract of heat-processed ginseng. Cancer Letters 150:41-48.

Kim BM, Kim DH, Park JH, Na HK, and Surh YJ. 2013a. Ginsenoside Rg3 Induces Apoptosis of Human Breast Cancer (MDA-MB-231) Cells. J Cancer Prev 18:177-185.

Kim HJ, Kim P, and Shin CY. 2013b. A comprehensive review of the therapeutic and pharmacological effects of ginseng and ginsenosides in central nervous system. J Ginseng Res 37:8-29. 10.5142/jgr.2013.37.8

Kim JS, Joo EJ, Chun J, Ha YW, Lee JH, Han Y, and Kim YS. 2012. Induction of apoptosis by ginsenoside Rk1 in SK-MEL-2-human melanoma. Arch Pharm Res 35:717-722. 10.1007/s12272-012-0416-0

Kim KR, Chung TY, Shin H, Son SH, Park KK, Choi JH, and Chung WY. 2010. Red Ginseng Saponin Extract Attenuates Murine Collagen-Induced Arthritis by Reducing Pro-inflammatory Responses and Matrix Metalloproteinase-3 Expression. Biol Pharm Bull Biological \& Pharmaceutical Bulletin 33:604-610.

Kim SN, Lee JH, Shin H, Son SH, and Kim YS. 2009. Effects of in vitro-digested ginsenosides on lipid accumulation in 3T3-L1 adipocytes. Planta Med 75:596-601. 10.1055/s-0029-1185358

Kim WY, Kim JM, Han SB, Lee SK, Kim ND, Park MK, Kim CK, and Park JH. 2000. Steaming of ginseng at high 
temperature enhances biological activity. J Nat Prod 63:1702-1704.

Kim YJ, Kwon HC, Ko H, Park JH, Kim HY, Yoo JH, and Yang HO. 2008. Anti-tumor Activity of the Ginsenoside Rk1 in Human Hepatocellular Carcinoma Cells through Inhibition of Telomerase Activity and Induction of Apoptosis. Biol Pharm Bull Biological \& Pharmaceutical Bulletin 31:826-830.

Kim YJ, Yamabe N, Choi P, Lee JW, Ham J, and Kang KS. 2013c. Efficient thermal deglycosylation of ginsenoside $\mathrm{Rd}$ and its contribution to the improved anticancer activity of ginseng. J Agric Food Chem 61:9185-9191. $10.1021 / \mathrm{jf} 402774 \mathrm{~d}$

Ko H, Kim Y, Park J, Park JY, and YANG HO. 2009. Autophagy Inhibition Enhances Apoptosis Induced by Ginsenoside Rk1 in Hepatocellular Carcinoma Cells. Bioscience, Biotechnology, and Biochemistry 73:21832189. $10.1271 / \mathrm{bbb} .90250$

Kwak JH, and Pyo JS. 2016. Characterization of Apoptosis Induced by Ginsenosides in Human Lung Cancer Cells. Analytical Letters 49:843-854.

Kwon SW, Han SB, Park IH, Kim JM, Park MK, and Park JH. 2001. Liquid chromatographic determination of less polar ginsenosides in processed ginseng. Journal of Chromatography A 921:335-339.

Lee JG, Lee YY, Kim SY, Pyo JS, Yun-choi HS, and Park JH. 2009. Platelet antiaggregating activity of ginsenosides isolated from processed ginseng. Pharmazie 64:602-604. 10.1691/ph.2009.9577

Lee S, Maharjan S, Kim K, Kim NJ, Choi HJ, Kwon YG, and Suh YG. 2010. Cholesterol-derived novel anti-apoptotic agents on the structural basis of ginsenoside Rk1. Bioorg Med Chem Lett 20:7102-7105. 10.1016/j.bmcl.2010.09.071

Lee SM. 2014. Anti-inflammatory effects of ginsenosides Rg5, Rz1 , and Rk1 : inhibition of TNF-alpha-induced NFkappaB, COX-2, and iNOS transcriptional expression. Phytother Res 28:1893-1896. 10.1002/ptr.5203

Lim SC, Maeng YS, Kwon JY, Kang MH, Hyang JH, Kim YH, Kwon YK, and Park YW. 2009. The effect of ginsenoside Rk1 in junctional protein of severe preeclamptic placenta. Korean Journal of Obstetrics and Gynecology 52:303-308.

Lim W, Mudge KW, and Vermeylen F. 2005. Effects of population, age, and cultivation methods on ginsenoside content of wild American ginseng (Panax quinquefolium). J Agric Food Chem 53:8498-8505. 10.1021/jf051070y

Liu JW, Tian SJ, Barry JD, and Luu B. 2007. Panaxadiol Glycosides that Induce Neuronal Differentiation in Neurosphere Stem Cells. J Nat Prod 70:1329-1334.

Maeng YS, Maharjan S, Kim JH, Park JH, Suk Yu Y, Kim YM, and Kwon YG. 2013. Rk1, a ginsenoside, is a new blocker of vascular leakage acting through actin structure remodeling. PLoS One 8:e68659. 10.1371/journal.pone.0068659

Moher D, A. L, J. T, and Altman DG. 2009. The PRISMA Group (2009). Preferred Reporting Items for Systematic Reviews and Meta-Analyses: The PRISMA Statement. BMJ 339. doi: 10.1136/bmj.b2535

Nag SA, Qin JJ, Wang W, Wang MH, Wang H, and Zhang R. 2015. Ginsenosides as Anticancer Agents: In vitro and in vivo Activities, Structure-Activity Relationships, and Molecular Mechanisms of Action. Front Pharmacol 
$3: 25$.

Nemmani KV, and Ramarao P. 2003. Ginsenoside Rf potentiates U-50,488H-induced analgesia and inhibits tolerance to its analgesia in mice. Life Sciences 72:759-768.

Park IH, Piao LZ, Kown SW, Lee YJ, Cho SY, Park MK, and Park JH. 2002. Cytotoxic Dammarane Glycosides from Processed Ginseng. Chem Pharm Bull 50:538-540.

Park JY, Choi P, Kim T, Ko H, Kim HK, Kang KS, and Ham J. 2015. Protective Effects of Processed Ginseng and Its Active Ginsenosides on Cisplatin-Induced Nephrotoxicity: In Vitro and in Vivo Studies. J Agric Food Chem 63:5964-5969. 10.1021/acs.jafc.5b00782

Ponnuraj SP, Siraj F, Kang S, Noh HY, Min JW, Kim YJ, and Yang DC. 2014. Amelioration of insulin resistance by Rk1 + Rg5 complex under endoplasmic reticulum stress conditions. Pharmacognosy Res 6:292-296.

Quan K, Liu Q, Wan JY, Zhao YJ, Guo RZ, Alolga RN, Li P, and Qi LW. 2015. Rapid preparation of rare ginsenosides by acid transformation and their structure-activity relationships against cancer cells. Sci Rep 5:8598.

Ryu J, Lee HW, Yoon J, Seo B, Kwon DE, Shin UM, Choi KJ, and Lee YW. 2016. Effect of hydrothermal processing on ginseng extract. J Ginseng Res. https://doi.org/10.1016/j.jgr.2016.12.002

Sato K, Mochizuki M, Saiki I, Yoo YC, Samukawa K, and Azuma I. 1994. Inhibition of tumor angiogenesis and metastasis by a saponin of Panax ginseng, ginsenoside-Rb2. Biol Pharm Bull 17:635-639.

Schlag EM, and McIntosh MS. 2006. Ginsenoside content and variation among and within American ginseng (Panax quinquefolius L.) populations. Phytochemistry 67:1510-1519. 10.1016/j.phytochem.2006.05.028

Shan X, Fu Y-S, Aziz F, Wang X-Q, Yan Q, and Liu J-W. 2014. Ginsenoside Rg3 Inhibits Melanoma Cell Proliferation through Down-Regulation of Histone Deacetylase 3 (HDAC3) and Increase of p53 Acetylation. PLoS One 9:e115401.

Shin BK, Kwon SW, and Park JH. 2015. Chemical diversity of ginseng saponins from Panax ginseng. J Ginseng Res 39:287-298. 10.1016/j.jgr.2014.12.005

Siddiqi MH, Siddiqi MZ, Ahn S, Kang S, Kim YJ, Veerappan K, Yang DU, and Yang DC. 2014. Stimulative Effect of Ginsenosides Rg5:Rk1 on Murine Osteoblastic MC3T3-E1 Cells. Phytotherapy Research 28:1447-1455. $10.1002 /$ ptr.5146

Song X, Zang L, and Hu S. 2009. Amplified immune response by ginsenoside-based nanoparticles (ginsomes). Vaccine 27:2306-2311. 10.1016/j.vaccine.2009.02.040

Sun Y, Liu Y, and Chen K. 2016. Roles and mechanisms of ginsenoside in cardiovascular diseases: progress and perspectives. Sci China Life Sci 59:292-298. 10.1007/s11427-016-5007-8

Tachikawa E, Kudo K, Harada K, Kashimoto T, Miyate Y, Kakizaki A, and Takahashi E. 1999. Effects of ginseng saponins on responses induced by various receptor stimuli. Eur J Pharmacol 369:23-32.

Tang W, Zhang Y, Gao J, Ding X, and Gao S. 2008. The Anti-fatigue Effect of 20(R)-Ginsenoside Rg3 in Mice by Intranasally Administration. Biol Pharm Bull 31:2024-2027.

Toh D, Pate DN, Chan EC, Teo A, Neo SY, and Koh HL. 2011. Anti-proliferative effects of raw and steamed extracts of Panax notoginseng and its ginsenoside constituents on human liver cancer cells. Chinese Medicine 6. 
621 Vuksan V, Sung MK, Sievenpiper JL, Stavro PM, Jenkins AL, Di Buono M, Lee KS, Leiter LA, Nam KY, Arnason

622 JT, Choi M, and A. N. 2008. Korean red ginseng (Panax ginseng) improves glucose and insulin regulation in well-controlled, type 2 diabetes: results of a randomized, double-blind, placebo-controlled study of efficacy and safety. Nutr Metab Cardiovasc Dis 18:46-56. 10.1016/j.numecd.2006.04.003

Xu T, Jin Z, Yuan Y, Wei H, Xu X, He S, Chen S, Hou W, Guo Q, and Hua B. 2016. Ginsenoside Rg3 Serves as an Adjuvant Chemotherapeutic Agent and VEGF Inhibitor in the Treatment of Non-Small Cell Lung Cancer: A Meta-Analysis and Systematic Review. Evid Based Complement Alternat Med. http://dx.doi.org/10.1155/2016/7826753

Xue P, Yao Y, Yang XS, Feng J, and Ren GX. 2017. Improved antimicrobial effect of ginseng extract by heat transformation. J Ginseng Res 41:180-187.

Yun TK. 2001. Panax ginseng-a non-organ-specific cancer preventive? The Lancet Oncology 2:49-55. 10.1016/s1470-2045(00)00196-0

Zhou J, Zhang HA, Lin Y, Liu HM, Cui YM, Xu Y, Zhao N, Ma JM, Fan K, and Jiang CL. 2014. Protective effect of ginsenoside against acute renal failure via reduction of renal oxidative stress and enhanced expression of ChAT in the proximal convoluted tubule and ERK1/2 in the paraventricular nuclei. Physiol Res 63:597-604. 


\section{$638 \quad$ Figure legends}

639 Figure 1. Chemical structure of the ginsenosides types - (A) protopanaxadiol (PPD)-type ginsneosides 640 including Rk1 represented in blue color, Rg5 represented in green color, and the rest of PPD-types are in 641 violet, (B) protopanaxatriol (PPT)-type ginsneosides represented in brown color, (C) Ocotillol- type 642 ginsneoside is represented in gray color, and (D) Oleanic acid-type ginsneosides are represented in red 643 color. glc, b-D-glucose; rha, a-L-rhamnose; arap, a-L-arabinose (pyranose); araf, a-L-arabinose (furanose) 644 Figure 2. Flowchart of our systematic review - summary of how the systematic search was conducted and eligible studies was identified (PRISMA flow diagram). PRISMA = Preferred Reporting Items for 646 Systematic reviews and Meta-Analyses.

647 Figure 3. Summary of G-Rk1 bioactivities and its mechanism of actions- ALP: alkaline phosphatase; 648 Bax: BCL2-Associated X Protein; Bcl-2: B-cell lymphoma 2; BMP 2: bone morphogenetic protein-2; 649 COX-2: Cyclooxygenase 2; CDK: cyclin-dependent kinase; erNSC: Epidermal growth factor-responsive 650 neurosphere stem cells; GSH: Glutathione; GLUT-4: Glucose Transporter; IL: interleukin; iNOS:

651 Inducible Nitric Oxide Synthase; IGF: insulin-like growth factor receptor; JNK: Jun N-terminal Kinase; 652 MMP3: Matrix Metalloproteinase 3; NF-kB: Nuclear Factor Kappa B; PARP: Poly ADP (Adenosine 653 Diphosphate)-Ribose Polymerase; TXB-2: Thromboxane B2; TNF- $\alpha$ : tumor necrosis factor. *The number 654 in the small circle indicate the number of studies that report this bioactivity. 


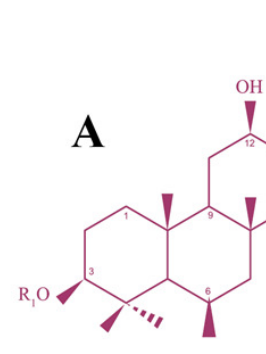

\begin{tabular}{|l|l|}
\hline No. & Ginsenoside \\
\hline
\end{tabular}

Ginsendoside Ra1

Ginsendoside Ra2

Ginsendoside Rb1

$4 \quad$ Ginsendoside $\mathrm{Rb} 2$

Ginsendoside $\mathrm{Rb3}$

Ginsendoside Rc

Ginsendoside Rd

20(S)-ginsendoside $\mathrm{Rg} 3$

\begin{tabular}{l|l}
$8 \mathrm{R}$ & 20(R)-ginsendoside $\mathrm{Rg} 3$
\end{tabular}

Ginsendoside $\mathrm{Rh} 2$

\begin{tabular}{l|l}
10 & Ginsendoside Rs1
\end{tabular}

11 Ginsendoside Rs2

12 Guinquenoside R1

13 Compound K

$14 \quad$ Chikusetsusaponin III

15 Ginsendoside Rk1

\begin{tabular}{l|l}
16 & Ginsendoside Rg5
\end{tabular}

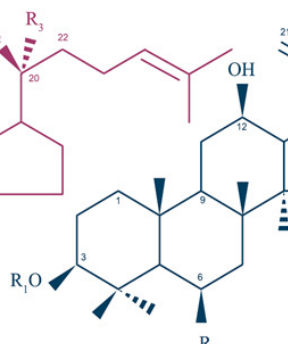

$\mathrm{R}$,

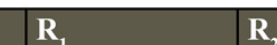

$\mathbf{R}_{2}$

$-\mathrm{glc}^{2}-\mathrm{glc}$

$-\mathrm{glc}^{2}-\mathrm{glc}$

$-\mathrm{glc}^{2}-{ }^{-} \mathrm{glc}$

$-\mathrm{glc}^{2}-{ }^{1} \mathrm{glc}$

$-\mathrm{glc}^{2}-{ }^{1} \mathrm{glc}$

$-\mathrm{glc}^{2}-{ }^{1} \mathrm{glc}$

$-\mathrm{glc}^{2}-{ }^{1} \mathrm{glc}$

$-\mathrm{glc}^{2}-\mathrm{glc}$

$-\mathrm{glc}^{2}-{ }^{-} \mathrm{glc}$

$-\mathrm{glc}$

$-\mathrm{glc}^{2}-{ }^{1} \mathrm{glc}^{6}-\mathrm{Ac}$

$-\mathrm{glc}^{2}-\mathrm{glc}^{6}-\mathrm{Ac}$

$-\mathrm{glc}^{2}-\mathrm{glc}^{6}-\mathrm{Ac}$

$-\mathrm{H}$

$-\mathrm{glc}^{2}-{ }^{1} \mathrm{glc}$

$\lambda_{x y l}$

$-\mathrm{glc}^{2}-{ }^{1} \mathrm{glc}$

$-\mathrm{glc}^{2}-\mathrm{g} l \mathrm{c}$

$-\mathrm{OH}$

$-\mathrm{OH}$

$-\mathrm{H}$

$-\mathrm{H}$

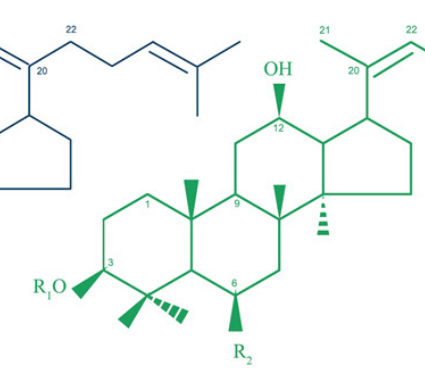

$\mathbf{R}_{3}$

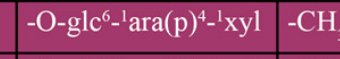

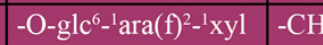

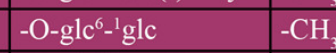

$-O-\mathrm{glc}^{6}-{ }^{-} \operatorname{ara}(\mathrm{p})$

$-O-g^{2}{ }^{2}{ }^{-} x y l$

$-\mathrm{O}-\mathrm{glc}^{2}-{ }^{1} \operatorname{ara}(\mathrm{f})$

$-\mathrm{O}$-glc

$-\mathrm{CH}_{3}$

$-\mathrm{CH}_{3}$

$-\mathrm{O}-\mathrm{glc}^{6}-{ }^{1} \operatorname{ara}(\mathrm{p})$

-O-glc ${ }^{6}-\operatorname{ara}(\mathrm{f})$

$-\mathrm{O}-\mathrm{glc}^{6}-{ }^{-} \mathrm{glc}$

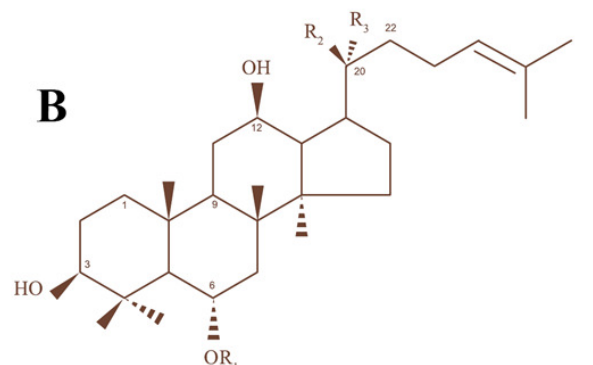

\begin{tabular}{|l|l|}
\hline No. & Ginsenoside \\
\hline
\end{tabular}

$\mathbf{R}_{1}$

7 Ginsendoside Re

18 Ginsendoside Rf

-glc ${ }^{2}-$ rha

9 Ginsendoside Rg1

$-\mathrm{glc}^{2}-{ }^{1} \mathrm{glc}$

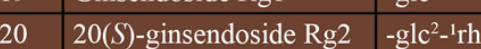

\begin{tabular}{l|l|l}
\hline 20R & 20(R)-ginsendoside Rg2 & -glc ${ }^{2}-$ rha \\
\hline
\end{tabular}

21 Ginsendoside $\mathrm{Rh} 1$

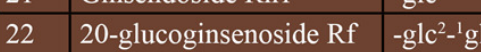

\begin{tabular}{|l|l}
23 & Notoginsenoside R \\
\hline
\end{tabular}

$-\mathrm{glc}^{2}-{ }^{1} x y 1$

24 Notoginsenoside R2

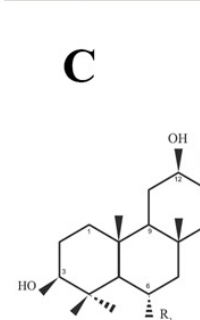

C

운<smiles>CC(C)(C)C(C)(C)C</smiles><smiles>CC1([Te])CCCC1</smiles><smiles>CC(C)C(C)C(C)C(C)C</smiles>

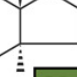

D

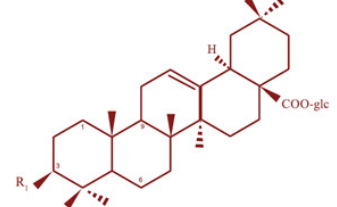

\begin{tabular}{|l|l|l}
\hline No. & Ginsenoside & $R_{1}$ \\
\hline
\end{tabular}

25 Majondoside R2 $-\mathrm{O}-\mathrm{glc}^{2}{ }^{\mathrm{I}} \mathrm{xyl}$

\begin{tabular}{l|l|l}
\hline 26 & Ginsendoside Ro & $-\mathrm{O}-\mathrm{glcUA}{ }^{2}-{ }^{1} \mathrm{glc}$ \\
\hline
\end{tabular}

27 Chikusetsusaponin IV $-\mathrm{O}$-glcUA ${ }^{4}-1$ ara(f)

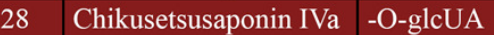


Total number $=317$
(1) Pubmed $=68$
(2) Virtual Health Library $=47$
(3) $\mathrm{WHO}$ GHL $=50$
(4) Google Scholar $=20$
(5) Scopus $=78$
(7) $\mathrm{SIGLE}=0$
(9) Pobline $=0$
(6) $\mathrm{ISI}=54$

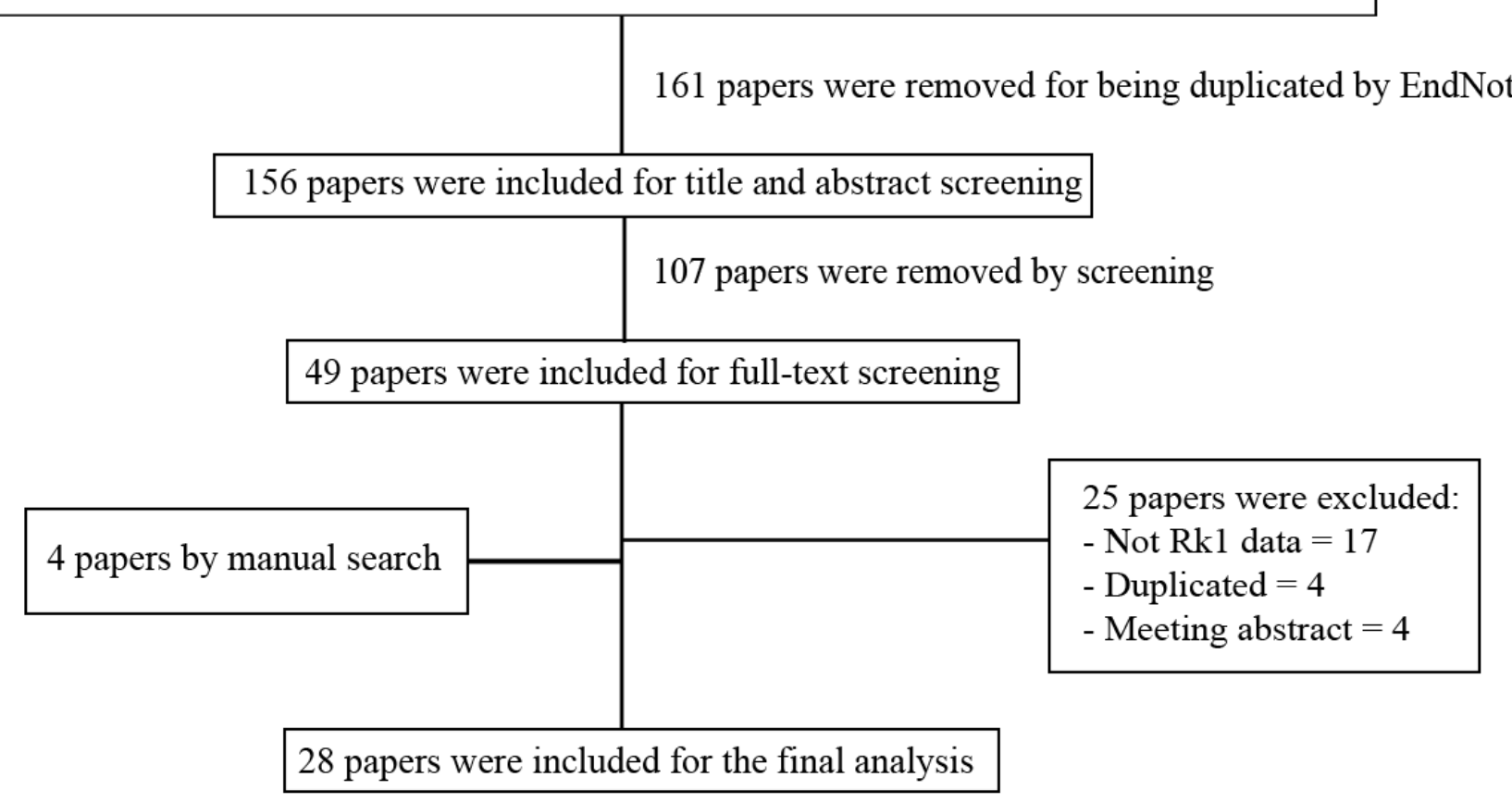




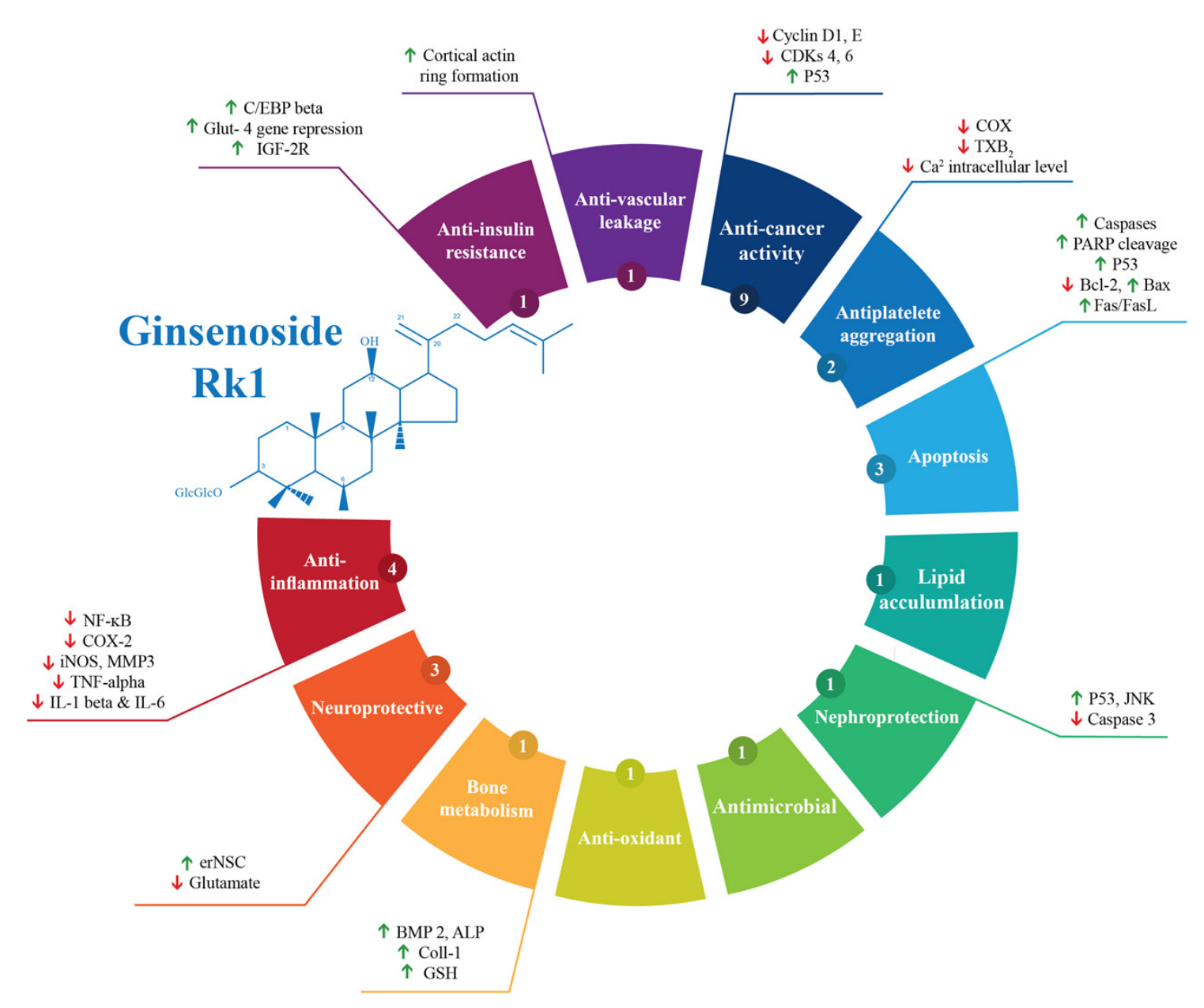


Table 1. Study characteristics of included articles.

663

\begin{tabular}{|c|c|c|c|c|}
\hline Author and Year & Country & Study design & Cell lines & Parameter Assessed \\
\hline Ko et al., 2009 & South Korea & In vitro & HepG2 & $\begin{array}{l}\text { Cell viability, cell proliferation, } \\
\text { inhibitory activity (IC50) }\end{array}$ \\
\hline Lee et al., 2014 & South Korea & In vitro & HepG2 & Cell viability \\
\hline Toh et al., 2011 & Singapore & In vitro & $\begin{array}{l}\text { SNU449 (CRL-2234), SNU182 (CRL- } \\
\text { 2235) and HepG2 (HB-8065) }\end{array}$ & Cell viability, cell proliferation \\
\hline Kim et al., 2008 & South Korea & In vitro & HepG2 & Cell viability, telomerase activity \\
\hline Park et al., 2002 & South Korea & In vitro & SK-Hep-1 cells & Cell viability \\
\hline Lim et al., 2009 & South Korea & In vitro & $\begin{array}{l}\text { Junctional proteins (zo-1, occludin and } \\
\text { plakoglobin) }\end{array}$ & ND \\
\hline Kim et al., 2009 & South Korea & In vitro & 3T3-L1 fibroblast cells & Cell viability, lipid accumulation \\
\hline Kim et al., 2012 & South Korea & In vitro & SK-MEL-2 human melanoma & Cell viability \\
\hline Ju et al., 2012 & South Korea & In vitro & Platelet & Antiplatelet aggregation activity \\
\hline
\end{tabular}




\begin{tabular}{|c|c|c|c|c|}
\hline Liu et al., 2007 & France & In vitro & $\begin{array}{l}\text { Embryonic neural stem cells } \\
\text { (neurospheres) }\end{array}$ & Neurogenic activity \\
\hline Lee et al., 2009 & South Korea & In vitro & Platelet & $\begin{array}{l}\text { Collagen }(3-4 \mu \mathrm{g} / \mathrm{L}) \text { induced platelet } \\
\text { aggregation }\end{array}$ \\
\hline Kim et al., 2010 & South Korea & In vivo & ND & TPA-induced mouse ear edema \\
\hline Maeng et al., 2013 & South Korea & $\begin{array}{l}\text { In vitro and } \\
\text { In vivo }\end{array}$ & HREC cells & $\begin{array}{l}\text { VEGF-induced retinal endothelial } \\
\text { permeability, VEGF-induced } \\
\text { destabilization of TJ protein ZO-1, } \\
\text { ZO-2 and occludin in membrane and } \\
\text { cytosol }\end{array}$ \\
\hline Kang et al., 2007 & Japan & In vitro & ND & The OH scavenging inhibition \\
\hline Kang et al., 2006 & Japan & In vitro & ND & The $\mathrm{OH}$ scavenging activities \\
\hline Lee et al., 2010 & South Korea & In vitro & HUVECs & Cell viability \\
\hline Kim et al., 2013a & South Korea & In vitro & Gastric cancer AGS cell & $\begin{array}{l}\text { Cell viability, the anticancer activity } \\
\text { of ginsenosides after heat processing } \\
\text { (IC50) }\end{array}$ \\
\hline
\end{tabular}




\begin{tabular}{|c|c|c|c|c|}
\hline Bao et al., 2005 & South Korea & $\begin{array}{l}\text { In vitro and } \\
\text { In vivo }\end{array}$ & $\begin{array}{l}\text { Cortical cell cultures containing } \\
\text { neuronal and non-neuronal cells }\end{array}$ & $\begin{array}{l}\text { Cognitive performance, } \\
\text { excitotoxicity induced by NMDA } \\
\text { and glutamate }\end{array}$ \\
\hline Park et al., 2015 & South Korea & $\begin{array}{l}\text { In vitro and } \\
\text { In vivo }\end{array}$ & LLC-PK1 cells & Cell viability \\
\hline Siddiqi et al., 2014 & South Korea & In vitro & The murine cell line, MC3T3-E1 & $\begin{array}{l}\text { Cell viability, mineralization, ALP } \\
\text { activity, collagen and glutathione }\end{array}$ \\
\hline Jing et al., 2006 & China & In vivo & ND & Cognitive performance \\
\hline Ponnuraj et al., 2014 & South Korea & In vitro & 3T3-L1 cells & Cell viability, glucose utilization \\
\hline Ahn et al., 2016 & South Korea & In vitro & HaCaT/RAW 264.7 & Anti-inflammation activity \\
\hline Hu et al., 2017 & China & In vivo & ND & Anti-inflammation activity \\
\hline Kwak et al., 2016 & South Korea & In vitro & A549 cell & Cell viability \\
\hline Quan et al., 2015 & China & In vitro & $\begin{array}{l}\text { A549, HCT-116, HepG2, Hela, MCF-7, } \\
\text { and PANC-1 cells }\end{array}$ & Cell viability \\
\hline Xue et al., 2017 & China & In vitro & ND & Antimicrobial activity \\
\hline
\end{tabular}


South Korea
ND

Ryu et al., $2017 \quad$ South Korea In vitro ND Anti-oxidant activity

A549 cell: human lung carcinoma; AMA: antimycin A; ALP: alkaline phosphatase; HaCaT: human keratinocyte cell line; HCT-116: human colon carcinoma; Hela: human cervical carcinoma; HepG2: human hepatocellular carcinoma cells; HUVEC: human umbilical vein endothelial cell; HRECs: Primary human retina microvascular endothelial cells; LLC-PK1: (pig kidney epithelium, CL-101); MCF-7: human breast adenocarcinoma; NMDA: N-methyl-D-aspartate; ND: not defined; PANC-1: human pancreatic cancer; SNU449, SNU182: Human liver cancer cell lines; RAW 264.7: the murine macrophage cell line; VEGF: vascular endothelial growth factor; TPA: 12-O-Tetradecanoyl- phorbol-13-acetate; TJ: tight junctions. 
Table 2. Summary of anti-cancer activity of G-Rk1.

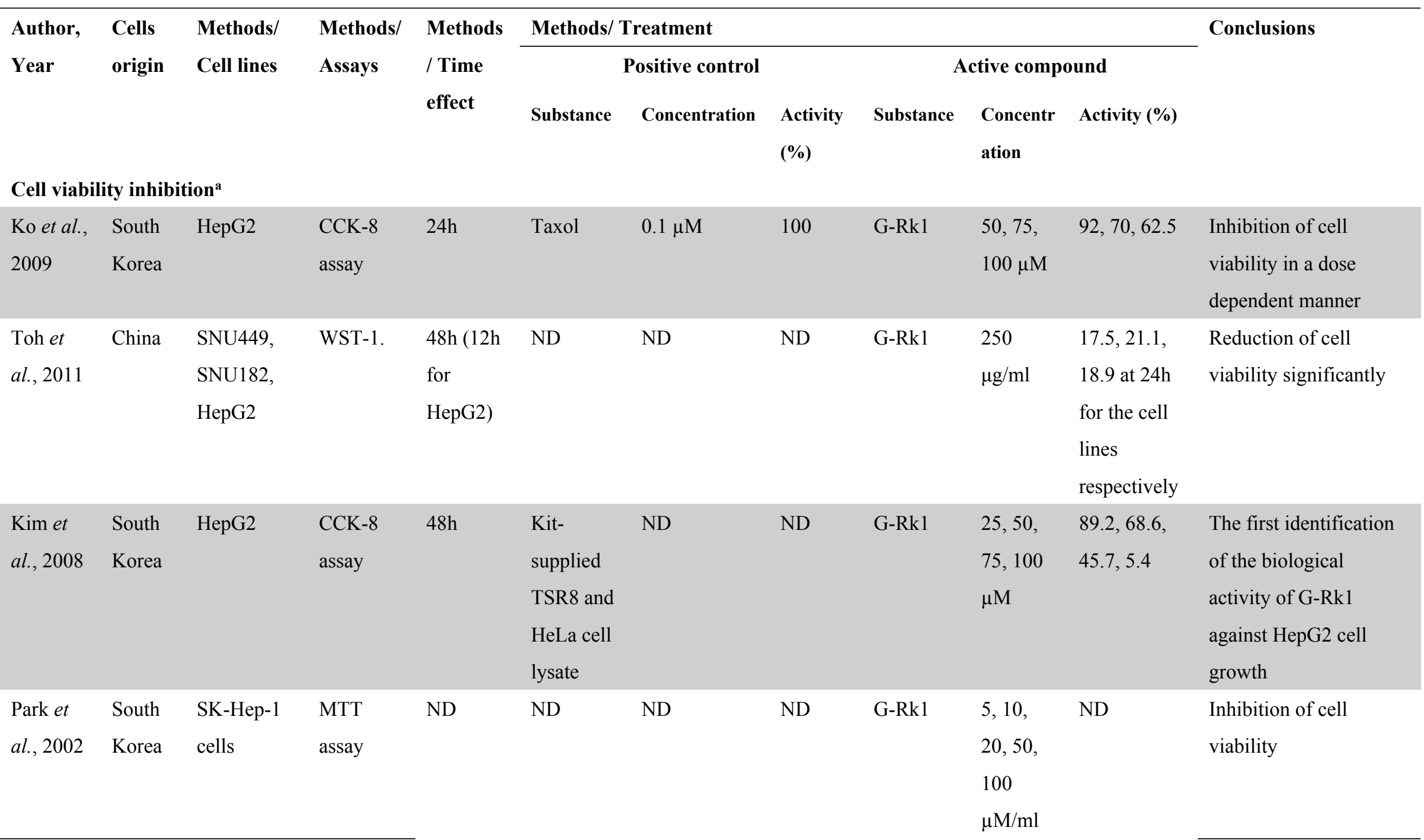




\begin{tabular}{|c|c|c|c|c|c|c|c|c|c|c|c|}
\hline \multirow[t]{2}{*}{$\begin{array}{l}\text { Kim et } \\
\text { al., } 2012\end{array}$} & $\begin{array}{l}\text { South } \\
\text { Korea }\end{array}$ & $\begin{array}{l}\text { SK-MEL-2 } \\
\text { human } \\
\text { melanoma }\end{array}$ & $\begin{array}{l}\text { Cell } \\
\text { viability } \\
\text { assay }\end{array}$ & $12 \mathrm{~h}$ & ND & ND & ND & G-Rk1 & $\begin{array}{l}5,10, \\
25,50, \\
75,100 \\
\mu \mathrm{M}\end{array}$ & $\begin{array}{l}100,96, \\
93.5,80, \\
60.5,18.2\end{array}$ & \multirow{2}{*}{$\begin{array}{l}\text { Inhibition of cell } \\
\text { viability of SK-Mel-2 } \\
\text { human melanoma cells } \\
\text { when they were } \\
\text { incubated with G-Rk1 } \\
\text { for } 24 \mathrm{~h} \text { and } 48 \mathrm{~h} \text {, at } \\
\text { concentrations }(0,10 \text {, } \\
25,50,75,100 \mu \mathrm{M}) \text { in } \\
\text { a dose dependent } \\
\text { manner }\end{array}$} \\
\hline & & & & $48 \mathrm{~h}$ & ND & ND & ND & G-Rk1 & $\begin{array}{l}5,10, \\
25,50, \\
75,100 \\
\mu \mathrm{M}\end{array}$ & $\begin{array}{l}93.3,90.5, \\
81,65.5 \\
40.5,8.8\end{array}$ & \\
\hline \multirow{2}{*}{$\begin{array}{l}\text { Lee } e t \\
\text { al., } 2010\end{array}$} & ND & HUVECs & MTT & $24 \mathrm{~h}$ & ND & ND & ND & G-Rk1 & 10 & 86.29 & \multirow{2}{*}{$\begin{array}{l}\text { Not related to G-Rk1 } \\
\text { activity }\end{array}$} \\
\hline & & & assay & $48 \mathrm{~h}$ & ND & ND & ND & & $\mu \mathrm{g} / \mathrm{ml}$ & 87.42 & \\
\hline $\begin{array}{l}\text { Kim et } \\
\text { al., } \\
2013 \mathrm{c}\end{array}$ & $\begin{array}{l}\text { South } \\
\text { Korea }\end{array}$ & $\begin{array}{l}\text { Gastric } \\
\text { cancer } \\
\text { AGS cell }\end{array}$ & $\begin{array}{l}\text { CCK-8 } \\
\text { assay }\end{array}$ & $24 \mathrm{~h}$ & ND & ND & ND & $\begin{array}{l}\text { G-Rg5/G- } \\
\text { Rk1 }\end{array}$ & $\begin{array}{l}0,12.5, \\
25,50, \\
100 \\
\mu \mathrm{g} / \mathrm{ml}\end{array}$ & $\begin{array}{l}100,98.81, \\
93.57, \\
93.57, \\
37.55,2.94\end{array}$ & $\begin{array}{l}\text { Inhibition of cell } \\
\text { viability in a dose } \\
\text { dependent manner }\end{array}$ \\
\hline $\begin{array}{l}\text { Kwak et } \\
\text { al., } 2016\end{array}$ & $\begin{array}{l}\text { South } \\
\text { Korea }\end{array}$ & A549 cell & $\begin{array}{l}\text { MTT } \\
\text { assay }\end{array}$ & $24 \mathrm{~h}$ & Cisplatin & $\begin{array}{l}5,10,25,50, \\
100 \mu \mathrm{M}\end{array}$ & $\begin{array}{l}84,73, \\
72,51 \\
37\end{array}$ & G-Rk1 & $\begin{array}{l}5,10, \\
25,50, \\
100 \mu \mathrm{M}\end{array}$ & $\begin{array}{l}87,83,83 \\
73,18\end{array}$ & $\begin{array}{l}\text { Inhibition of cell } \\
\text { viability in a dose } \\
\text { dependent manner }\end{array}$ \\
\hline \multirow[t]{3}{*}{$\begin{array}{l}\text { Quan et } \\
\text { al. } 2015\end{array}$} & \multirow[t]{3}{*}{ China } & HepG2 cell & $\begin{array}{l}\text { MTT } \\
\text { assay }\end{array}$ & $24 \mathrm{~h}$ & ND & ND & ND & G-Rk1 & $\begin{array}{l}5,10 \\
20,40\end{array}$ & $\begin{array}{l}85,111, \\
105,23,15\end{array}$ & \multirow[t]{3}{*}{$\begin{array}{l}\text { Reduction of cell } \\
\text { viability }\end{array}$} \\
\hline & & A549 cell & & & & & & & $80 \mu \mathrm{M}$ & $\begin{array}{l}97,93,110, \\
47,3.6\end{array}$ & \\
\hline & & НCТ-116 & & & & & & & & $99,103,70$ & \\
\hline
\end{tabular}




\begin{tabular}{|c|c|}
\hline cell & $6.5,5.4$ \\
\hline \multirow[t]{2}{*}{ Hala cell } & 113,116 \\
\hline & $119,36,11$ \\
\hline \multirow[t]{2}{*}{ MCF-7 cell } & 125,127 \\
\hline & $123,84,8.6$ \\
\hline PANC-1 & 98,115 \\
\hline cell & $104,24,9.9$ \\
\hline
\end{tabular}

\section{Cell proliferation inhibition ${ }^{b}$}

\begin{tabular}{|c|c|c|c|c|c|c|c|c|c|c|c|}
\hline $\begin{array}{l}\text { Ko et al., } \\
2009\end{array}$ & $\begin{array}{l}\text { South } \\
\text { Korea }\end{array}$ & HepG2 & $\begin{array}{l}\text { CCK-8 } \\
\text { assay }\end{array}$ & $24 \mathrm{~h}$ & Taxol & $0.1 \mu \mathrm{M}$ & 100 & G-Rk1 & $\begin{array}{l}50,75, \\
100 \mu \mathrm{M}\end{array}$ & $8,30,37.5$ & $\begin{array}{l}\text { G-Rk1 inhibits cell } \\
\text { proliferation in the } \\
\text { early stage of G-Rk1- } \\
\text { induced apoptosis cell } \\
\text { line. }\end{array}$ \\
\hline $\begin{array}{l}\text { Toh et } \\
\text { al., } 2011\end{array}$ & China & SNU449 & WST-1. & $48 \mathrm{~h}$ & ND & ND & ND & G-Rk1 & $100 \mu \mathrm{M}$ & 50 & $\begin{array}{l}\text { G-Rk1 inhibit cell } \\
\text { proliferation in the } \\
\text { SNU449 cell line }\end{array}$ \\
\hline \multicolumn{12}{|c|}{ Apoptotic activity } \\
\hline $\begin{array}{l}\text { Kim et } \\
\text { al., } 2008\end{array}$ & $\begin{array}{l}\text { South } \\
\text { Korea }\end{array}$ & HepG2 & $\begin{array}{l}\text { CCK-8 } \\
\text { assay }\end{array}$ & $48 \mathrm{~h}$ & ND & ND & ND & G-Rk1 & $100 \mu \mathrm{M}$ & ND & $\begin{array}{l}\text { G-Rk1 induced an } \\
\text { increase in the fraction } \\
\text { of early apoptotic cells } \\
\text { from } 0.46 \text { to } 16.23 \% \text {. }\end{array}$ \\
\hline
\end{tabular}




\begin{tabular}{|c|c|c|c|c|c|c|c|c|c|c|c|}
\hline $\begin{array}{l}\text { Kim et } \\
\text { al., } 2012\end{array}$ & $\begin{array}{l}\text { South } \\
\text { Korea }\end{array}$ & $\begin{array}{l}\text { SK-MEL-2 } \\
\text { human } \\
\text { melanoma }\end{array}$ & $\begin{array}{l}\text { FAS/FAS } \\
\mathrm{L} \\
\text { antagonist } \\
\text { analysis }\end{array}$ & $24 \mathrm{~h}$ & $\begin{array}{l}\text { Fas/FasL } \\
\text { antagonist } \\
\text { Kp 7-6 }\end{array}$ & $1 \mathrm{mM}$ & ND & G-Rk1 & $\begin{array}{l}5,10, \\
50,100 \\
\mu \mathrm{M}\end{array}$ & $\begin{array}{l}96,93.5 \\
79.5,18.7\end{array}$ & $\begin{array}{l}\text { The apoptotic effect of } \\
\text { G-Rk1 might be } \\
\text { influenced by other } \\
\text { pathways }\end{array}$ \\
\hline \multirow[t]{2}{*}{$\begin{array}{l}\text { Hu et al., } \\
2017\end{array}$} & \multirow[t]{2}{*}{ China } & \multirow[t]{2}{*}{ Mice } & $\begin{array}{l}\text { Expressio } \\
n \text { of Bax }\end{array}$ & \multirow[t]{2}{*}{ ND } & \multirow[t]{2}{*}{ APAP } & \multirow[t]{2}{*}{$250 \mathrm{mg} / \mathrm{kg}$} & 90.7 & \multirow[t]{2}{*}{$\begin{array}{l}\text { G-Rk1 + } \\
\text { APAP }\end{array}$} & \multirow[t]{2}{*}{$\begin{array}{l}10,20 \\
\mathrm{mg} / \mathrm{kg}\end{array}$} & $25.5,39.8$ & \multirow{2}{*}{$\begin{array}{l}\text { G-Rk1 has apoptotic } \\
\text { effect by increasing } \\
\text { Bax expression and } \\
\text { decreasing Bcl-2 }\end{array}$} \\
\hline & & & $\begin{array}{l}\text { Expressio } \\
\mathrm{n} \text { of } \mathrm{Bcl}-2\end{array}$ & & & & 12.6 & & & $65.7,50.5$ & \\
\hline
\end{tabular}

APAP: acetaminophen; A549 cell: human lung carcinoma; Bax: BCL2-Associated X Protein; Bcl-2: B-cell lymphoma 2; CCK-8: Cell Counting Kit-8; HaCaT: human

keratinocyte cell line; HCT-116: human colon carcinoma; Hela: human cervical carcinoma; HepG2: human hepatocellular carcinoma cells; HUVEC: human umbilical vein endothelial cell; LLC-PK1: (pig kidney epithelium, CL-101); MCF-7: human breast adenocarcinoma; MTT: 3-(4,5-dimethyl-thiazol-2yl) -2,5-diphenyl tetrazolium bromide; MC3T3-E1: (RCB1126, an osteoblast-like cell line derived from C57BL/6 mouse calvarias); PANC-1: human pancreatic cancer; SNU449, SNU182: Human 
Table 3. Summary of the effects of G-Rk1 on antiplatelet aggregation, anti-inflammatory, anti-vascular leakage, nephroprotective effect, neuroprotective effect, bone metabolism, anti-insulin resistance effect, and lipid accumulation.

\begin{tabular}{|c|c|c|c|c|c|c|c|c|c|c|c|}
\hline \multirow{3}{*}{$\begin{array}{l}\text { Author, } \\
\text { Year }\end{array}$} & \multirow{3}{*}{$\begin{array}{l}\text { Cells } \\
\text { origin }\end{array}$} & \multirow{3}{*}{$\begin{array}{l}\text { Methods/ } \\
\text { Cell lines }\end{array}$} & \multirow{3}{*}{$\begin{array}{l}\text { Methods/ } \\
\text { Assays }\end{array}$} & \multirow{3}{*}{$\begin{array}{l}\text { Methods/ } \\
\text { Time } \\
\text { effect }\end{array}$} & \multicolumn{6}{|c|}{ Methods/ Treatment } & \multirow[t]{3}{*}{ Conclusions } \\
\hline & & & & & \multirow[b]{2}{*}{ Substance } & \multicolumn{2}{|l|}{ Positive control } & \multicolumn{3}{|c|}{ Active compound } & \\
\hline & & & & & & Concentration & Activity & Substance & Concentration & Activity & \\
\hline \multicolumn{12}{|c|}{ Antiplatelet aggregation } \\
\hline Ju et al., & South & Platelet & A & ND & ASA & $50 \mu \mathrm{M}$ & ND & G-Rk1 & $50 \mu \mathrm{M}$ & ND & G-Rk1 strongly inhibited \\
\hline \multirow[t]{3}{*}{2012} & Korea & & UPLC/Q- & & & & & & & & platelet aggregation at 50 \\
\hline & & & TOF MS & & & & & & & & $\mu \mathrm{M}$ compared with ASA \\
\hline & & & system & & & & & & & & \\
\hline Lee $e t$ & South & Platelet & Turbidim & ND & ASA & $66 \mu \mathrm{M}$ & 50 & G-Rk1 & $3 \mu \mathrm{M}$ & $50^{\mathrm{a}}$ & G-Rk1 exhibited 22-fold \\
\hline \multirow[t]{3}{*}{ al., 2009} & Korea & & etrically & & & & & & & & inhibitory effect of that of \\
\hline & & & & & & & & & & & ASA on AA-induced \\
\hline & & & & & & & & & & & aggregation \\
\hline \multicolumn{12}{|c|}{ Anti-inflammatory activity } \\
\hline Lee $e t$ & South & HepG2 & NF-кB- & $1 \mathrm{~h}$ & Sulfasalaz & $0.54 \mu \mathrm{M}$ & 50 & G-Rk1 & $0.75 \mu \mathrm{M}$ & $50^{\mathrm{a}}$ & G-Rk1 exhibited the \\
\hline al., 2014 & Korea & & luciferase & & ine & & & & & & potentials as anti- \\
\hline
\end{tabular}




\begin{tabular}{|c|c|c|c|c|c|c|c|c|c|c|c|}
\hline & & & assay & & & & & & & & inflammatory substance \\
\hline \multirow{5}{*}{$\begin{array}{l}\text { Kim et } \\
\text { al., } 2010\end{array}$} & South & Collagen- & Edema & $4 \mathrm{~h}$ & ND & ND & ND & G-Rk1 & $10,50 \mathrm{mg} / \mathrm{kg}$ & 9.09 & G-Rk1 exhibited anti- \\
\hline & Korea & induced & & & & & & & & $7.83^{\mathrm{b}}$ & inflammatory activity on \\
\hline & & mouse & & & & & & & & & collagen-induced mouse \\
\hline & & arthritis & & & & & & & & & arthritis \\
\hline & & model & & & & & & & & & model \\
\hline \multirow{8}{*}{$\begin{array}{l}\text { Ahn et } \\
\text { al., } 2016\end{array}$} & South & $\mathrm{HaCaT} / \mathrm{R}$ & $\mathrm{TARC} / \mathrm{C}$ & $1 \mathrm{~h}$ & TNF- $\alpha$ & $10 \mathrm{ng} / \mathrm{mL}$ & 157 & G-Rg5/G- & $1,25,50$ & 118 & The results suggesting G- \\
\hline & Korea & AW & CL17 & & & & $\mathrm{pg} / \mathrm{ml}$ & $\mathrm{Rk} 1+$ & $\mu \mathrm{g} / \mathrm{ml}$ & 104 & $\mathrm{Rg} 5 / \mathrm{G}-\mathrm{Rk} 1$ as a promising \\
\hline & & 264.7 & & & & & & TNF- $\alpha$ & & 95.4 & natural therapy in the \\
\hline & & & & & & & & & & $\mathrm{pg} / \mathrm{ml}$ & control of atopic \\
\hline & & & $\mathrm{MDC} / \mathrm{CC}$ & & & & 243 & & & 215 & dermatitis \\
\hline & & & L22 & & & & $\mathrm{pg} / \mathrm{ml}$ & & & 209, & \\
\hline & & & & & & & & & & 189 & \\
\hline & & & & & & & & & & $\mathrm{pg} / \mathrm{ml}$ & \\
\hline \multirow[t]{2}{*}{ Hu et } & China & & Expressio & $1 \mathrm{~h}$ & APAP & $250 \mathrm{mg} / \mathrm{kg}$ & 156 & G-Rk1 + & $10,20 \mathrm{mg} / \mathrm{kg}$ & $87,96.7$ & G-Rk1 has a protective \\
\hline & & & $n$ of & & & & $\mathrm{ng} / \mathrm{L}$ & APAP & & $\mathrm{ng} / \mathrm{L}$ & effect against APAP \\
\hline
\end{tabular}




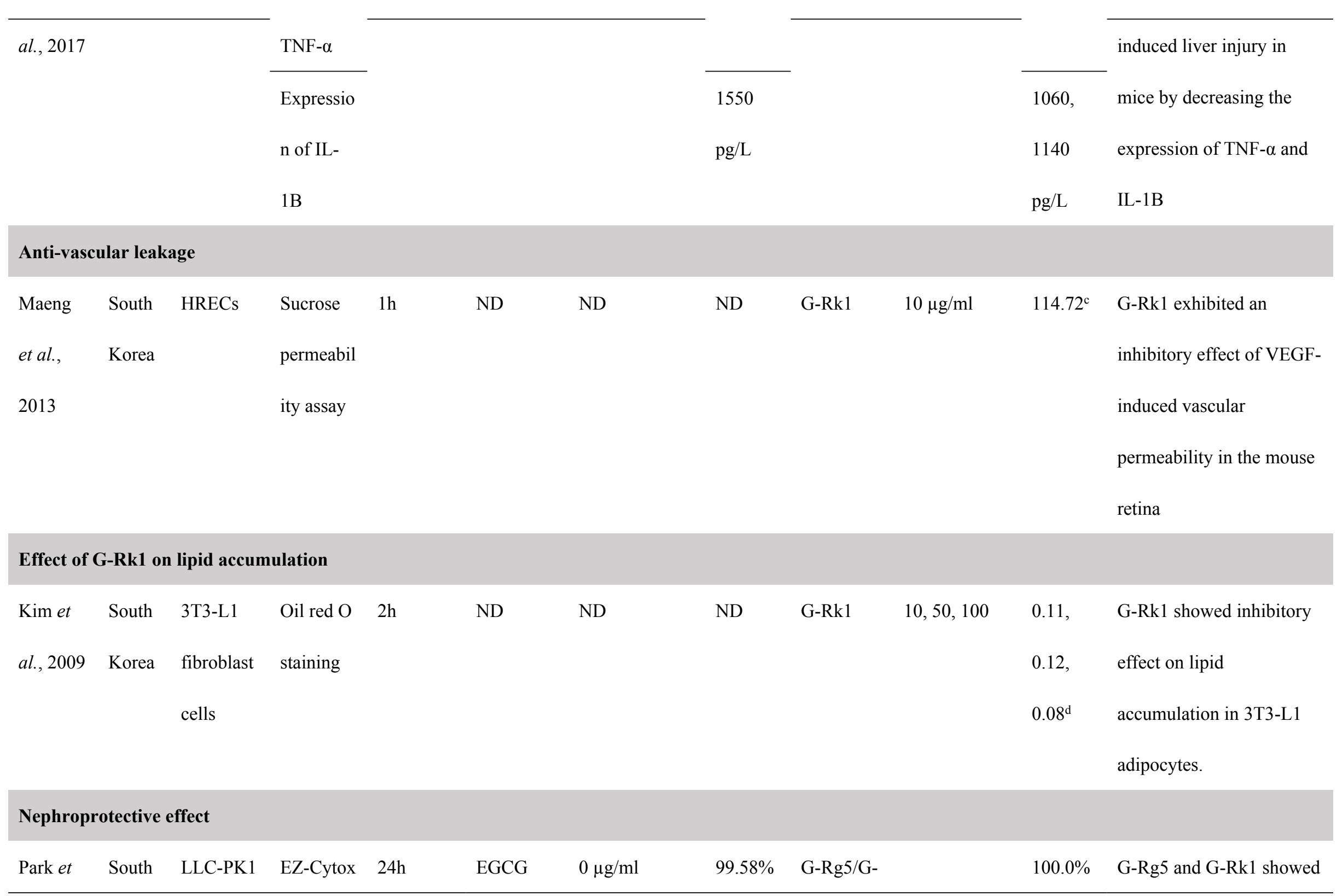




\begin{tabular}{|c|c|c|c|c|c|c|c|c|c|c|c|}
\hline \multirow[t]{6}{*}{ al., 2015} & \multirow[t]{6}{*}{ Korea } & \multirow[t]{6}{*}{ cells } & \multirow{2}{*}{\multicolumn{2}{|c|}{$\begin{array}{l}\text { cell } \\
\text { viability }\end{array}$}} & \multicolumn{3}{|l|}{ (without } & \multicolumn{3}{|l|}{ Rk1 } & \multirow{3}{*}{$\begin{array}{l}\text { a protective effect against } \\
\text { cisplatin-induced } \\
\text { nephrotoxicity in cultured }\end{array}$} \\
\hline & & & & & & & & & & & \\
\hline & & & \multicolumn{2}{|l|}{ assay kit } & EGCG & $0,50,100,250$ & 40.76 & G-Rg5/G- & $0,50,100$ & 40.23 & \\
\hline & & & & & & $\mu \mathrm{g} / \mathrm{ml}$ & 46.34 & Rk1 & $250 \mu \mathrm{g} / \mathrm{ml}$ & 45.23 & kidney cells and mice. \\
\hline & & & & & & & 47.33 & (cisplatin & & 57.32 & \\
\hline & & & & & & & $38.65 \%$ & $25 \mathrm{uM})$ & & $80.21 \%$ & \\
\hline \multicolumn{12}{|c|}{ Bone metabolism } \\
\hline Siddiqi & South & The & MTT & $24 h+48 h$ & AMA & $60 \mu \mathrm{g} / \mathrm{ml}$ & $99.33 \%$ & G-Rg5/G- & $1,10,20,30$ & 109.21, & G-Rg5/G-Rk1 enhances \\
\hline et al., & Korea & murine & assay & & & & & G-Rk1 + & $50 \mu \mathrm{g} / \mathrm{ml}$ & 111.54, & cell growth of MC3T3-E1 \\
\hline \multirow[t]{4}{*}{2014} & & cell line, & & & & & & AMA & & 123.43, & cells in a dose-dependent \\
\hline & & MC3T3- & & & & & & & & 131.21, & manner, also in presence \\
\hline & & E1 & & & & & & & & 140.05 & of AMA \\
\hline & & & & & & & & & & $\%$ & \\
\hline \multicolumn{12}{|c|}{ Neuroprotective effect } \\
\hline Bao et & South & Mice & ND & ND & Ethanol & $3 \mathrm{~g} / \mathrm{kg}$ & 34.5 & G-Rg5/G- & $10 \mathrm{mg} / \mathrm{kg}$ & 45.68 & G-Rg5/G-G-Rk1 \\
\hline al., 2005 & Korea & & & & & & $44.22^{\mathrm{e}}$ & G-Rk1 & & $207.48^{\mathrm{e}}$ & significantly reversed the \\
\hline
\end{tabular}


scopolamine

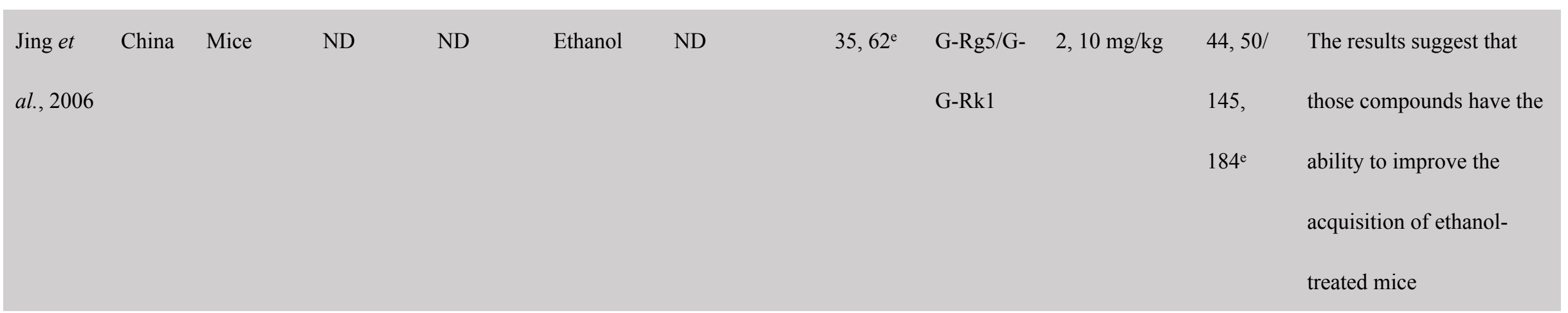

Anti-insulin resistance effect

\begin{tabular}{|c|c|c|c|c|c|c|c|c|c|c|c|}
\hline Ponnuraj & South & 3T3-L1 & MTT & $24 \mathrm{~h}$ & ND & ND & 1.36 & G-Rg5/G- & $25,50,75$ & 1.4, & G-Rk1 increases the IGF- \\
\hline et al., & Korea & & assay & & & & & Rk1 & $100 \mu \mathrm{g} / \mathrm{ml}$ & 1.36 & $2 \mathrm{R}$ and glucose utilization \\
\hline \multirow[t]{7}{*}{2014} & & & & & & & & & & 1.33, & in adipocytes. \\
\hline & & & & & & & & & & $1.31^{*}$ & \\
\hline & & & & & Tunicamy & $2 \mu \mathrm{g} / \mathrm{ml}$ & 0.73 & G-Rg5/G- & & 1.4, & \\
\hline & & & & & $\operatorname{cin}$ & & & Rk1 & & 1.47, & \\
\hline & & & & & & & & (under & & 1.5 & \\
\hline & & & & & & & & Tunicamy & & $1.54^{*}$ & \\
\hline & & & & & & & & $\operatorname{cin} 2$ & & & \\
\hline
\end{tabular}




\section{$\mu \mathrm{g} / \mathrm{ml})$}

AA: arachidonic acid; AMA: antimycin A; ASA: acetylsalicylic acid; APAP: acetaminophen; A549 cell: human lung carcinoma; Bax: BCL2-Associated X Protein; Bcl-2: 